\title{
Toward an optimized strategy of using various airway mucus clearance techniques to treat critically ill COVID-19 patients
}

\author{
Mingzhi LUO*; KaI NI; Yan SUN; Jia GUO; Kang WEN; Linhong DENG* \\ Changzhou Key Laboratory of Respiratory Medical Engineering, Institute of Biomedical Engineering and Health Sciences, Changzhou University, Changzhou, \\ 213164, China
}

Key words: COVID-19, Airway mucus, Rheology, Mechanical force, Airway clearance techniques

\begin{abstract}
Coronavirus disease 2019 (COVID-19) caused by acute respiratory syndrome coronavirus 2 (SARS-Cov-2) is still threatening the human life and society throughout the world. For those critically ill patients, mechanical ventilation (MV) is essential to provide life support during treatment. However, both the virus infection and MV disrupt the balance between secretion and elimination of airway mucus and lead to mucus accumulation in the lung. Postmortem examination verified that the lungs in patients died of COVID-19 are indeed filled with sticky mucus, suggesting a great need to improve airway mucus clearance in critically ill COVID-19 patients. Therefore, it may be helpful to comprehensively review the current understanding regarding the changes of biochemical and rheological features of airway mucus associated with the disease, as well as the physiological principles and algorithm to decide airway clearance techniques suitable for the critically ill COVID-19 patients. Based on these considerations, optimized strategies may be developed to eliminate the airway mucus accumulated in the airways of critically ill COVID-19 patients.
\end{abstract}

$\begin{array}{ll}\text { Abbreviations } & \\ \text { ACTs: } & \text { airway clearance techniques } \\ \text { ARDS: } & \text { acute respiratory distress syndrome } \\ \text { COVID-19: } & \text { coronavirus disease } 2019 \\ \text { EPP: } & \text { equal pressure point } \\ \text { FRC: } & \text { functional residual capacity } \\ \text { HFCWO: } & \text { high frequency chest wall oscillation } \\ \text { Hi-PEP: } & \text { high pressure positive expiratory pressure } \\ \text { MCC: } & \text { mucociliary clearance } \\ \text { MHI: } & \text { manual hyperinflation } \\ \text { MI-E: } & \text { mechanical insufflation-exsufflation } \\ \text { MV: } & \text { mechanical ventilation } \\ \text { Osc-PEP: } & \text { oscillating positive expiratory pressure } \\ \text { PCL: } & \text { periciliary layer } \\ \text { PEF: } & \text { peak expiratory flow } \\ \text { PEP: } & \text { positive expiratory pressure } \\ \text { PIF: } & \text { peak inspiration flow } \\ \text { SARS-CoV-2: } & \text { severe acute respiratory syndrome } \\ \text { VHI: } & \text { coronavirus 2 } \\ & \text { ventilator hyperinflation }\end{array}$

*Address correspondence to: Mingzhi Luo, luomingzhi@cczu.edu.cn; Linhong Deng, dlh@cczu.edu.cn

Received: 16 May 2020; Accepted: 23 September 2021

\section{Introduction}

Coronavirus disease 2019 (COVID-19) caused by severe acute respiratory syndrome coronavirus 2 (SARS-CoV-2) is still threatening human health worldwide (Sohrabi et al., 2020). COVID-19 patients usually start with common symptoms such as cough and fever, but within two weeks some of them will become either severely (15\%) or critically ill (5\%) suffering from acute respiratory distress syndrome (ARDS) and even respiratory failure, and most critically ill COVID-19 patients need mechanical ventilation (MV) to provide respiratory support (Brewster et al., 2020; Cascella et al., 2021; Huang et al., 2020; Wu and McGoogan, 2020; Yam et al., 2003; Yang et al., 2020). Unfortunately, these mechanically ventilated COVID-19 patients are still risk an over $50 \%$ fatality rate (Baden and Rubin, 2020; Cao et al., 2020; Murthy et al., 2020; Wang et al., 2020; Xie et al., 2020).

One of the main reasons for this unacceptably high mortality may be the suffocating mucus accumulation in the airways (Chen et al., 2020). Indeed, airway mucus accumulation or even mucus plug has been observed in both proximal bronchi and peripheral small airways in critically ill COVID-19 patients (Liu et al., 2020a; Lu et al., 2021; Xu et al., 2020). In addition, airway mucus accumulation is thought to result in a common feature of lung opacity in severe COVID-19 patients (Dunican et al., 2018) and severe 
hypoxemic respiratory failure in a significant proportion of COVID-19 patients (Brosnahan et al., 2020; Wu et al., 2020). It has also been suggested that airway mucus accumulation may lead to silent hypoxia, i.e., oxygen deprivation without breathing problems, which is presented as a unique lifethreatening feature of COVID-19 (Khan et al., 2021; Liu et al., 2020b). Airway mucus accumulation is generally associated with respiratory viral infection, but is known to be deteriorated by $\mathrm{MV}$, which may be responsible for airway obstruction and loss of pulmonary function in mechanically ventilated critically ill COVID-19 patients (Chen et al., 2019b; Fahy and Dickey, 2010). Therefore, it is very important to properly manage airway mucus accumulation in COVID-19 patients, especially those critically ill and mechanically ventilated patients (Brosnahan et al., 2020; Cook et al., 2020; Saracoglu et al., 2020; Szarpak et al., 2020).

In clinical practice, airway mucus accumulation can be managed by either pharmacological intervention using mucus thinning and expectorant drugs or physical intervention using so-called airway clearance techniques (ACTs) (Balsamo et al., 2010; Belli et al., 2021; Castro et al., 2013; Fan et al., 2017; Gosselink et al., 2008; Poole and Black, 2003; Rogers and Barnes, 2006). In fact, a spectrum of ACTs have been proved effective in helping clearing airway mucus accumulation such as postural drainage, breathing maneuvers, manual hyperinflation and mechanical assistive devices, and some of them have been recommended in several therapy guidelines for COVID-19 patients (Belli et al., 2021; Murthy et al., 2020; Thomas et al., 2020). However, there have been few comprehensive and updated reviews focusing on different ACTs in regards of their working mechanisms and efficacies, which is not helpful to fully understand the pros and cons of different ACTs in treating different cases of airway mucus accumulation and thus prevent optimization of ACTs application in treating critically ill COVID-19 patients (Battaglini et al., 2020; Denehy and Berney, 2006; Lazzeri et al., 2020; Thomas et al., 2020; Vitacca et al., 2020).

Therefore, in this review article we first summarize the changes of biochemical and rheological properties of airway mucus and the correlated risk factors of airway mucus accumulation, especially in COVID-19 patients. Then, we focus on the basic rationales for airway mucus clearance and the associated ACTs that may be suitable for critically ill COVID-19 patients. Based on such deep understanding of airway mucus accumulation and ACTs, an optimized strategy may be established for application of ACTs in management of airway mucus accumulation in critically ill COVID-19 patients (Ambrosino and Clini, 2015; Stiller, 2000).

\section{Airway Mucus Accumulation in COVID-19 Patients}

In COVID-19, it has been reported that a large proportion of the patients present symptoms of cough $(67.8 \%)$ and sputum production (33.7\%), both of which are known to be associated with excessive airway mucus secretion (Guan et al., 2020; Wang et al., 2020). These data suggest that airway mucus accumulation may be a common phenomenon in COVID-19, due to a combination of dysfunction of mucociliary clearance (MCC), airway mucus hypersecretion, and changed rheology as described in the following.
Mucociliary clearance in healthy subjects and COVID-19 patients

Airway mucus in healthy subjects usually acts as an essential protective physical barrier by forming a thin layer on top of the airway lumen and then constructing MCC together with cilia (about 200 per cell, 6-7 $\mu \mathrm{m}$ long). Under the cyclic beatings of cilia including a fast effective stroke and a slow recovery stroke $(10 \sim 15 \mathrm{~Hz})$, the inhaled particles and pathogens can be trapped in the airway mucus and eliminated from the airway system (Fig. 1) (Loreng and Smith, 2017; McAuley et al., 2019; Ridley and Thornton, 2018; Roy et al., 2014; Sanderson and Sleigh, 1981; Widdicombe, 1997; Xu and Jiang, 2019b).

According to its location to cilia, the airway mucus layer can be divided into an apical high viscosity layer (mucus gel, 10-50 $\mu \mathrm{m}$ depth) and a bottom low viscosity layer (periciliary layer, PCL, $7 \mu \mathrm{m}$ depth) (Button et al., 2012; Thornton and Sheehan, 2004). Since the height of cilia is similar to the depth of PCL layer, most of the movements of cilia occur in the PCL layer. Therefore, during the effective strokes the cilia intermittently sweep the subside of the mucus gel, which leads to the mucus cephalad transport $(\sim 100 \mu \mathrm{m} / \mathrm{s})$ (Silberberg, 1990). This high turnover rate of airway mucus by MCC is a major feature of the respiratory system in healthy subjects. However, in COVID-19 patients, SARS$\mathrm{CoV}-2$ infection is known to seriously disrupt the function of MCC. For example, it has been reported that SARS-CoV-2 infection inadvertently leads to the shedding of ciliated cells from the airway epithelium (Fang et al., 2020). This is partly because that a subpopulation of the ciliated cells highly express ACE2 and TMPRSS2 and thus mediate the initial infection and cellular entry of SARS-CoV-2 (Chilvers et al., 2001; Lee et al., 2020; Sungnak et al., 2020; Ziegler et al., 2020; Zou et al., 2020). In addition, it has been demonstrated in a reconstituted human bronchial epithelial model that SARS-CoV-2 preferentially replicates in ciliated cells, which causes a rapid loss of the ciliary layer and thus compromises the motile function of the cilia (Brosnahan et al., 2020). On the other hand, the intrinsic epithelial defense mechanisms likely occur too late to prevent such cilia loss due to SARS-CoV-2 infection (Robinot et al., 2020).

Apart from the structural dysfunction of MCC, SARSCoV-2 also disrupts the cilia beating through interference with the physiologically relevant signaling that modulates the cilia beating frequency, such as ATP, acetylcholine, cyclic adenosine monophosphate, cyclic guanosine monophosphate, nitric oxide, and inositol trisphosphate (Essaidi-Laziosi et al., 2018; Kuek and Lee, 2020). Both the structural and signaling dysfunctions of the airway epithelium and the airway cilia would inevitably reduce the ability of MCC to remove airway mucus from the lung, which partially explains why airway mucus accumulation is so common and severe in critically ill COVID-19 patients.

\section{Airway mucins in healthy subjects and COVID-19 patients}

The principal components of airway mucus both structurally and functionally are mucins, and there are at least nine types of them in human airways (Chatterjee et al., 2020; Lillehoj et al., 2013). Among these mucins, MUC1, MUC4 and MUC16 mainly locate in the PCL layer tethered to the plasma 


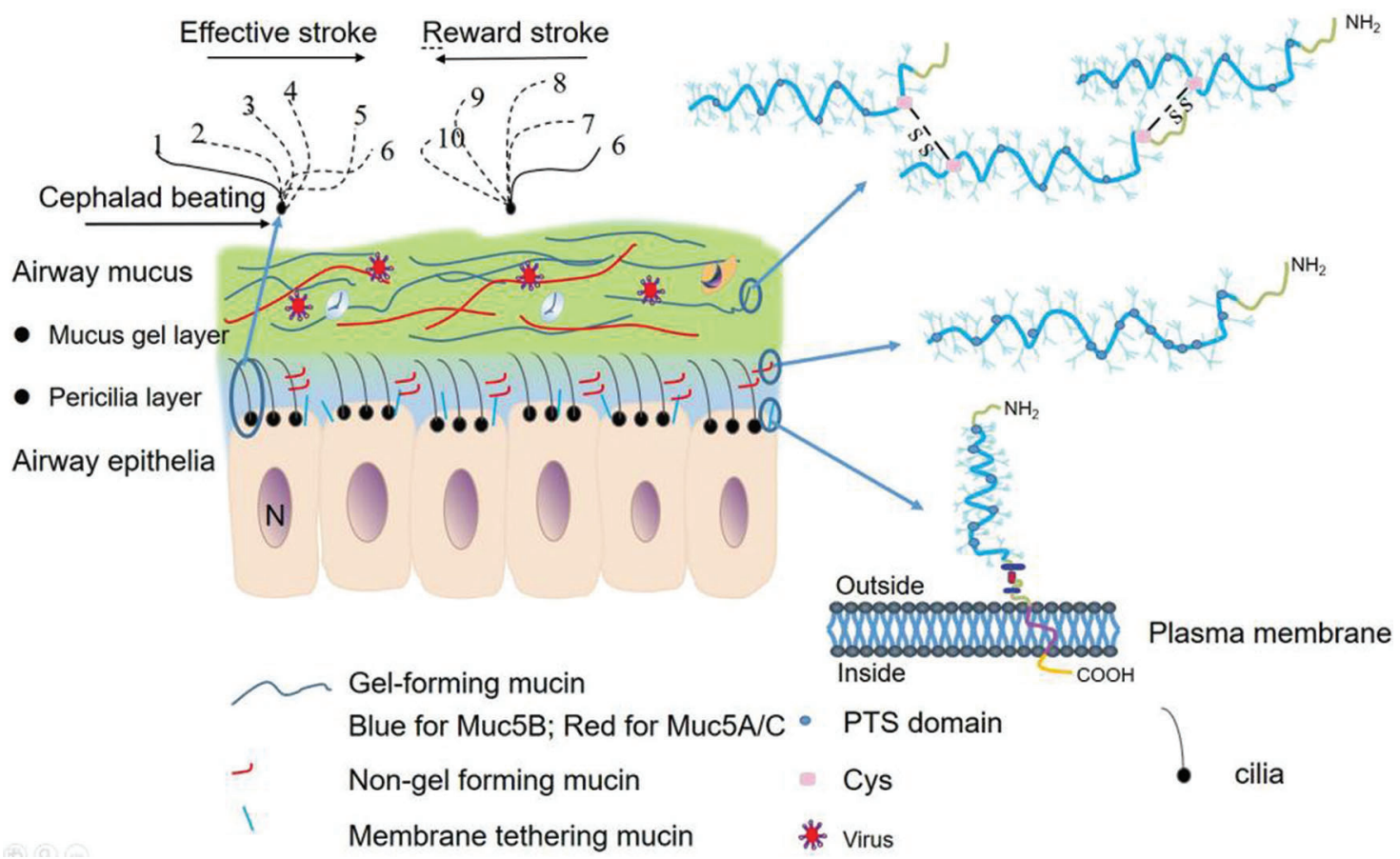

FIGURE 1. Mucociliary clearance (MCC) acts as a protective barrier in airways during SARS-CoV-2 infection, adapted from (Chatterjee et al., 2020; Denneny et al., 2020; Hattrup and Gendler, 2008; Kuek and Lee, 2020; Xu and Jiang, 2019b). MCC consists of airway mucus and respiratory cilia. The major components of airway mucus are gel forming mucins (MUC5AC and MUC 5B, entrapping the virus and clearing them out driven by the continuous beating of cilia) and transmembrane mucins (MUC1, MUC4, and MUC16, binding to virus via the interaction of adhesion and sialic acid to prevent the entry of virus into cells), both of which are highly glycosylated proteins.

membrane of airway epithelium via a transmembrane domain, which attract water, thereby forming a lubricate fluid layer surrounding and protecting the cilia to promote movement of the mucus gel above. The gel-forming MUC2, MUC5A/C, MUC5B and MUC19, and the non-gel forming MUC7 and MUC8 mainly locate in the mucus gel layer after secretion by goblet cells (Fig. 1) (Denneny et al., 2020; Dhanisha et al., 2018; Fahy and Dickey, 2010; Hattrup and Gendler, 2008; Ridley and Thornton, 2018; Thornton et al., 2008).

Airway mucins always contain highly repeated domains of proline, threonine and serine. Since both threonine and serine mediate glycosylation via their oxygen, airway mucins are thus heavily glycosylated (20\% protein core and $80 \%$ carbohydrates). In addition, the gel-forming mucins also contain abundant cysteine, which mediates the non-covalent and covalent crosslinks between the ends of different mucins due to their hydrophobic property and the disulfide formation, respectively. Consequently, the gel-forming mucins form polymers up to $5 \mu \mathrm{m}$ long from only $0.2-$ $0.6 \mu \mathrm{m}$ long mucin monomers (Bansil et al., 1995; Sheehan et al., 1991). Once secreted, these heavily glycosylated long polymeric mucins interact with ions and absorb water and then increase the volume by several hundred times within seconds, forming a three dimensional lattice hydrostatic mucus gel (Quraishi et al., 1998). Therefore, the airway mucus in the gel layer acquires both viscosity and elasticity, a physical property that is characteristic of complex fluids.

Besides their roles in determining airway mucus physical properties, airway mucins also have vital roles in protection of airways from infection by viruses such as SARS-CoV-2. For example, it has been shown that the terminal sialic acid glycans in gel-forming mucins including MUC5AC and
MUC5B can facilitate the interaction with coronavirus (Ganesan et al., 2013). Consequently, the airway mucins may act as the primary site to entrap the viral particles and then remove them from the respiratory tract via MCC. The finding that COVID-19 patients have a higher level of MUC5B than their healthy counterparts seems to corroborate the protective role for MUC5B in this disease (Iyer et al., 2020).

In addition, MUC1, MUC4 and MUC16 in the PCL layer (transmembrane mucins) can bind to coronavirus such as SARS-CoV-2 via the interaction of adhesion and sialic acid, which may prevent the entry of virus into the airway cells (Chatterjee et al., 2020; Zou et al., 2020). The transmembrane mucins are also known to shed their extracellular domains from the cell surface into the airway lumen, which is cleavaged by endogenous protease that is activated due to mucin-virus interactions (McAuley et al., 2017). Therefore, transmembrane mucins such as MUC1, MUC4, and MUC16 located on the surface of cilia can act as releasable decoy receptors and prevent the virus infection (Chatterjee et al., 2020).

\section{Hypersecretion of airway mucins in COVID-19 patients}

In COVID-19 patients, the expression of airway mucins may be enhanced in response to SARS-CoV-2 infection via several signaling pathways, which leads to airway mucus accumulation (Bose et al., 2021; Khan et al., 2021; Plante et al., 2020). For example, SARS-CoV-2 infection may stimulate differentiation and hyperplasia of the goblet cells in the airways, which is followed by hyperproduction and secretion of mucins. Up to date, enhanced expression of various mucins particularly MUC1, MUC2, and MUC4, 
MUC5AC, MUC5B, and retention of highly viscous mucus in bronchial airways have been observed in COVID-19 patients (Chen et al., 2020; Leng et al., 2020; Lu et al., 2021; Wang et al., 2020; Ye et al., 2020; Zhang et al., 2021).

One of the causes of airway mucin hypersecretion in COVID-19 is the SARS-CoV-2 induced excessive inflammatory response known as cytokine storm, which is summarized by Castelli et al. (2020) in their review article. Briefly, numerous cytokines facilitate mucin expression via various signaling pathways. Among them, IL-2, IL-4, IL-8, IL-9, IL-13 and IL-19 facilitate mucin expression via activation of STATs signaling, IL- $1 \beta$, IL-5, IL-6, and IL-19 facilitate mucin expression via activation of MAPK signaling, while EGF, ATP and adenosine facilitate mucin expression via activation of NF- $\kappa \beta$ signaling. In addition, it has been reported that SARS-CoV-2 increased IFN- $\beta / \gamma$ expression, which enhanced expression of airway mucins such as MUC1, MUC2, MUC5AC, MUC5B, MUC13 and MUC16 via activation of IDO1-AhR axis (Hadjadj et al., 2020; Liu et al., 2020b). Since cytokine storm is a general feature in critically ill COVID-19 patients, these patients are also generally associated with airway mucin hypersecretion (Wang et al., 2020).

The role of airway mucus rheology in COVID-19 patients Airway mucus is a material that behaves like both a viscous fluid and a soft elastic solid, a rheological feature known as viscoelasticity. This airway mucus rheology can be impacted by virus infection and thus differently modulates the cilia beating and mucus transport.

\section{Changes of airway mucus rheology in COVID-19 patients}

In COVID-19 it has been reported that a proportion of the critically ill patients are often seen with highly viscous airway mucus that even forms colloidal mucus plugs in the bronchioles (Wang et al., 2020). The abnormal rheological properties and mucus accumulation/plugging in the COVID-19 patients may result from various factors such as increased content of solids in the airway mucus (up to $15 \%$ as reported by (Button et al., 2016) as well as changes in hydration, $\mathrm{pH}$, and ion composition of the airway mucus (Ridley and Thornton, 2018).

The risk of mucus accumulation in critically ill COVID-19 patients

In healthy persons, mucus is continuously secreted into airways with totally about $10-100 \mathrm{~mL} /$ day. Under the function of MCC, mucus will move from peripheral airways to the glottis, and then be cleared by swallowing or coughing (Button et al., 2012; Dickey, 2018). For critically ill COVID-19 patients, viral infection and the following inflammatory responses lead to airway mucus accumulation by changing mucus viscoelasticity, stimulating mucus hypersecretion, and disturbing mucus elimination as described above (Button et al., 2016; Ridley and Thornton, 2018; Wang et al., 2020).

Once the sticky airway mucus accumulates in the airways, it provides a favorable growth media for bacteria (Konrad et al., 1994; Li Bassi et al., 2008; Safdar et al., 2005). Bacterial infection will cause airway inflammation, which then induces goblet cells hyperplasia and submucosal gland hypertrophy, and leads to further mucus secretion and thus a vicious cycle of infection, inflammation, and hypersecretion. Additionally, the sticky airway mucus leads to the shedding of ciliated cells and impairs ciliary beating, and thus disrupts the function of MCC. Both the increased secretion of sticky airway mucus and the impaired MCC will further accelerate airway mucus accumulation (Anderson et al., 2015; Zahm et al., 1989).

Airway mucus accumulation can increase airway resistance and thus deteriorate lung function presenting as decreased forced expiratory volume in one second, which will lead to atelectasis, ARDS, ultimately the total obstruction of respiratory tracts and respiratory failure (Cerveri and Brusasco, 2010; Chen et al., 2019b; Curran and Cohn, 2010; Darbee et al., 2005; Dunican et al., 2018; Fahy and Dickey, 2010; Hogg, 2004; Sprung et al., 2010). Therefore, airway mucus accumulation may be one of the causatives for the high death rate of critically ill COVID-19 patients (Chen et al., 2020; Lu et al., 2021; Zhang et al., 2021), and aggressive management of airway mucus accumulation by using appropriate ACTs is essential in clinical practice of treating respiratory conditions including critically ill COVID-19 patients (McKim et al., 2011; Thomas et al., 2020).

The direct impact of rheology on the transport of airway mucus Airway mucus rheology determines the efficacy of MCC via modulating the mechanical coupling between the cilia and the mucus (Macchione et al., 1995; Quraishi et al., 1998; Rajendran and Banerjee, 2020; Silberberg, 1983). Therefore, a suitable viscoelasticity is required for the airway mucus to facilitate the conversion of energy from the cilia beating into mucus movement. Indeed, it has been widely reported that the airway mucus with an elastic modulus at 1-2 $\mathrm{Pa}$ and a zero shear rate viscosity (yield) $12 \mathrm{~Pa} \cdot \mathrm{s}\left(0.01 \mathrm{~s}^{-1}\right)$ is most suitable for the function of MCC (Majima et al., 1991; Puchelle et al., 1987; Rubin et al., 1990; Shih et al., 1977). Studies have also shown that the ratio of elasticity to viscosity and the overall impedance rather than viscosity and elasticity alone are more significantly associated with the function of MCC (Lorenzi et al., 1992).

Interestingly, airway mucus can switch between viscous and elastic features depending on the magnitude of external deformation rates (Chen et al., 2019a; Cone, 2009). For example, when it is sheared airway mucus undergoes a process of thinning due to a temporary realignment of mucins (Volsko, 2013). Because of these, several types of mechanical force including gravitational force, friction force, shearing force, and adhesion force may function together to determine the airway mucus rheological features and thus correlate the tendency of mucus movement (Fig. 2). This confers the ability of external mechanical forces due to tidal breathing $(0.3 \mathrm{~Hz})$, ciliary beating $(10-15 \mathrm{~Hz})$, forced expiratory maneuvers to regulate mucus rheology and the following mucus transport (Branson, 2007; Lai et al., 2009).

Based on the rheological response of airway mucus to different external forces, it is possible to develop a variety of ACTs for clinical usage. For example, gravity, oscillation, and inspiration/expiration flow have been utilized to 
Expiratory flow

Under certain shearing force
(1) Suitable viscoelasticity: flowing up

FIGURE 2. Mechanical forces and the rheological features of airway mucus that determine airway mucus movement.

modulate airway mucus transport. Indeed, using in vitro and in vivo models, it has been reported that oscillation of mucus can decrease its viscoelasticity in a time, frequency, and magnitude-dependent manner. Interestingly, the oscillation to reduce mucus viscoelasticity is found to be most potent at $12-15 \mathrm{~Hz}$, which is similar to the cilia beating frequency (App et al., 1998). Therefore, oscillation-based working mechanisms have been developed and integrated into different types of ACTs (Huang et al., 2020; Rogers, 2007; Zhu et al., 2020).

\section{Basic Rationales for Clearance of Mucus from Obstructed Airways}

Current methodologies for clearance of mucus-obstructed airways are all based on utilizing different physiological processes to effectively eliminate airway mucus, such as ventilating behind the obstructed airways/alveoli, increasing expiratory flow rate/flow bias, enhancing the beating of the cilia and decreasing the viscosity of airway mucus (Ambrosino and Clini, 2015; Denehy and Berney, 2006; Kim, 1997; Lester and Flume, 2009; McCarren and Alison, 2006; Pathmanathan et al., 2015; Rogers and Doull, 2005). The basic rationales for these methods are discussed in detail as below.

Ventilating behind the obstructed airways/alveoli

If mucus obstructs the airways/alveoli, ventilating behind the obstructed regions is helpful to push the retained airway mucus out, which can be realized via interdependence of the adjacent alveoli and the collateral channels as shown in Fig. 3 (Cetti et al., 2006; Terry and Traystman, 2016).

For obstructed alveoli that are adjacent and physically interconnected, the expansion of alveoli exerts traction forces and opens adjacent collapsed alveoli, thereby assisting ventilation to these regions, which is called interdependence of adjacent alveoli (McIlwaine et al., 2017).
For obstructed airways especially the peripheral small airways, ventilation can be realized through some collateral channels that connect from either bronchioles to bronchioles (channels of Martin), bronchioles to alveoli (channels of Lambert) or alveoli to alveoli (pores of Kohn, $\sim 50$ /alveolus). Once the airways are obstructed, these collateral channels can assist ventilation behind the obstructed regions to promote clearing the airway mucus since airflow prefers the path of least resistance (Slebos and Shah, 2017).

Ventilation through these accessory pathways can be generated by holding breath, increasing inspiratory flow rate/volume, and increasing positive pressure, which forms the basis of several ACTs such as breathing maneuvers, hyperinflation, and positive expiratory pressure (PEP) (Branson, 2007). In addition to ventilation behind the obstructed airways/alveoli, there are several other ways to physically enhance the fluidity and thus clearance of airway mucus that are discussed respectively in the following.

\section{Increasing expiratory flow}

Expiratory airflow especially peak expiratory flow (PEF) provides shearing forces on airway mucus surface to mobilize its cephalad movement via a two-phase gas-liquid flow mechanism (Fig. 4) (Kim et al., 1986a; Kim et al., 1987; Kim et al., 1986b; Leith, 1968). Basically, once the shearing force exceeds the surface tension and the adhesive force of the mucus gel layer, the airway mucus starts to flow concurrently with the expiratory airflow in a pattern dependent on the magnitude of PEF, i.e., the expiratory air flows as either 1) fine bubbles in the airway mucus (bubble flow) for $\mathrm{PEF}<18 \mathrm{~L} / \mathrm{min}$; 2) large plugs in the airway mucus (plug flow) for PEF at $18-300 \mathrm{~L} / \mathrm{min} ; 3$ ) a core inside an annulus of airway mucus (annular flow) for PEF at 300-750 $\mathrm{L} / \mathrm{min}$; or 4) fine drops combined with airway mucus (mist flow) for PEF $>750 \mathrm{~L} / \mathrm{min}$. Among them, both the annular and mist flows can initiate cephalad movement of retained 


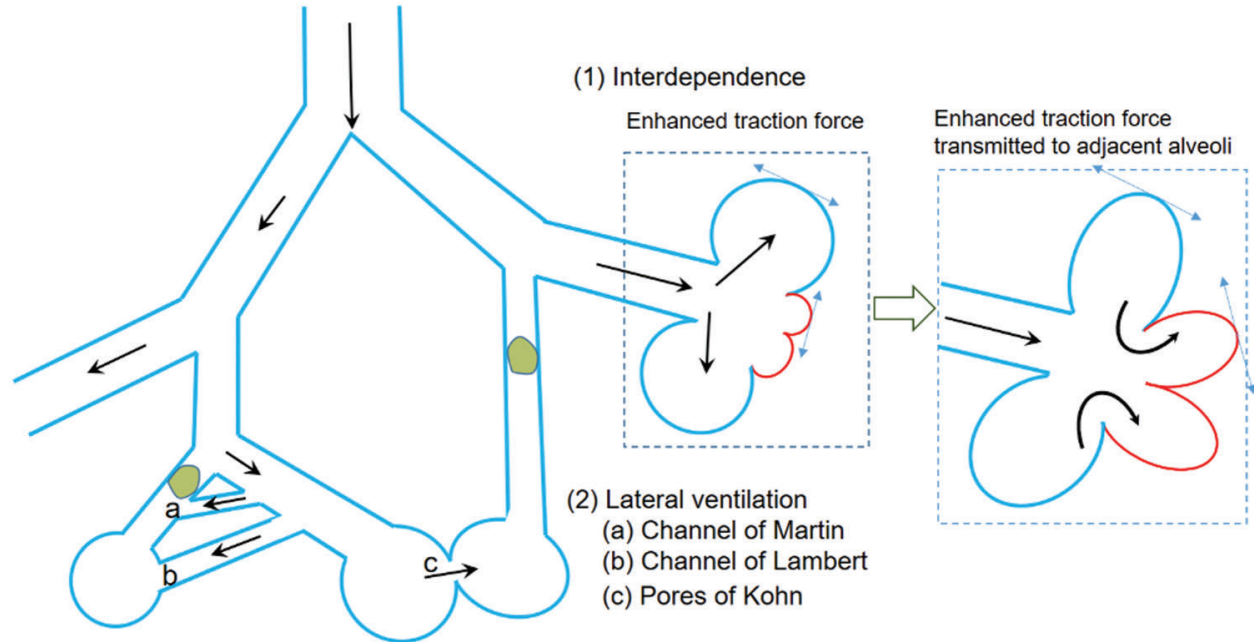

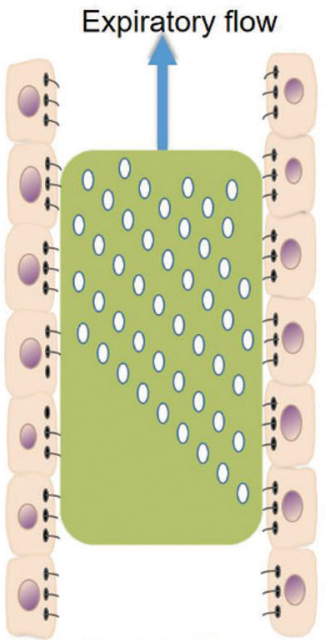

Bubble flow

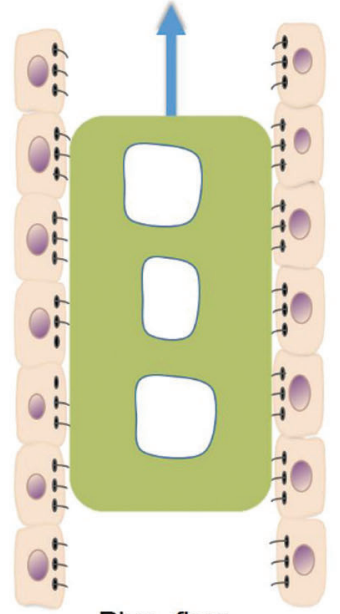

Plug flow

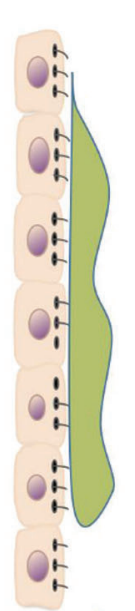

Annular flow

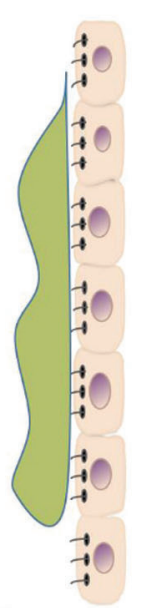

$750 \mathrm{~L} / \mathrm{min}$
FIGURE 3. The accusatory pathways for ventilation in airways/alveoli, adapted from (Cetti et al., 2006; Terry and Traystman, 2016).

FIGURE 4. Four different flow patterns of expiratory airflow combined with concurrent airway mucus flow in the airway tract, adapted from Kim et al. (1986a); Kim et al. (1987); Kim et al. (1986b); Leith (1968).

airway mucus (Kim et al., 1986a; Kim et al., 1987; Kim et al., 1986b; Leith, 1968).

It is generally known that PEF is proportional to the intrapulmonary pressure and inversely proportional to the airway resistance. Therefore, increasing the intrapulmonary pressure and decreasing the airway resistance have been used to increase PEF for airway mucus clearance in various ACTs (Maxwell and Ellis, 1998). For example, spontaneous forced expiration maneuvers such as cough and huff, mechanical device assistance such as mechanical insufflation-exsufflation (MI-E) can be used to generate increased intrapulmonary pressure. In addition, according to Poiseuille's law the airway resistance (R) is proportional to the length (l) and inversely proportional to the $4^{\text {th }}$ power of radius ( $\mathrm{r}$ ) of the airways tract, as well as proportional to the viscosity $(\eta)$ of air and the airway mucus $\left(R=8 \eta 1 / \pi r^{4}\right)$. Therefore, the airway resistance can be decreased by either increasing airway radius via hyperinflation or decreasing the viscosity of the airway mucus via shearingthinning by cough, huff, and MI-E (Kim et al., 1987).

On the other hand, the intrapulmonary pressure during forced expiratory will gradually decrease from the alveoli to the mouth because of frictional pressure loss, and there will be a point where the intrapulmonary pressure equals to the surrounding pleural pressure (i.e., equal pressure point, EPP) (Oberwaldner, 2000). From the EPP toward the mouth in the downstream, the pleural pressure exceeds the intrapulmonary pressure and airway compression occurs, which narrows the airway transiently and thus increases PEF and favors a cephalad mucus flow according to Bernoulli's principle (Fig. 5) (Hollandl and Buttonl, 2006; Kaminsky and Chapman, 2020; van der Schans, 2007).

The location of EPP is mainly determined by the expiratory force and the elastic recoil of the lung, which usually occurs in the central airways. This is why cough and huff are usually effective for clearing airway mucus in the central airways especially above the sixth or seventh generations of airway branching (Button and Button, 2013; Oberwaldner, 2000). However, increasing expiratory force and elastic recoil can shift the site of EPP toward the alveoli, which provides the rationale for ACTs to clear airway mucus in small airways and alveoli by using enhanced force expiratory flow, PEP, and high frequency chest wall 
A

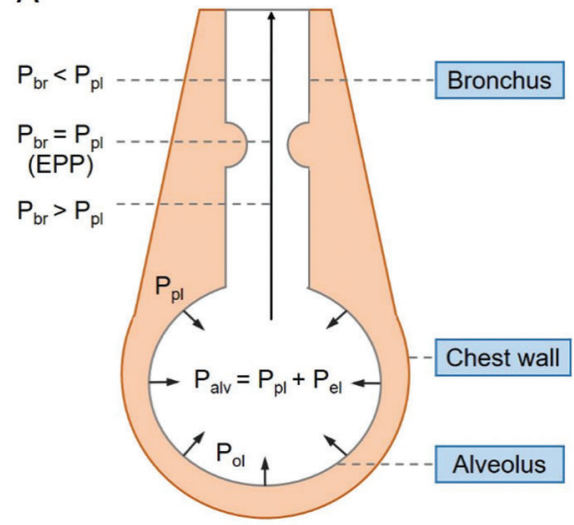

B

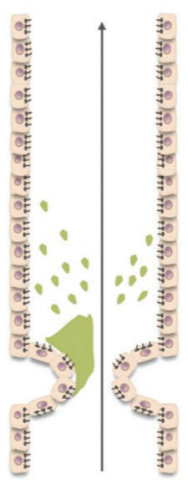

FIGURE 5. Mobilization of airway mucus via equal pressure point (EPP), adapted from Oberwaldner (2000); van der Schans (2007). (A) Expiratory flow with slight airway compression from EPP. $\mathrm{P}_{\mathrm{br}}$ : pressure in bronchus; $\mathrm{P}_{\mathrm{pl}}$ : pressure in pleural; $\mathrm{P}_{\mathrm{al}}$ : pressure in alveolus; $\mathrm{P}_{\mathrm{e}}$ : pressure induced by elastic recoil of lung. (B) The choke point catches the mucus and creates turbulent flow, which aerosolizes the mucus.

oscillation (HFCWO). Since the elastic recoil of the lung is also determined by the lung volume, it is another rationale for ACTs to remove mucus from the distal and central airways by using low and high lung volumes, respectively (Fink, 2007).

\section{Increasing cephalad-bias flow}

In addition to increasing expiratory flow, the flow bias between inspiratory and expiratory flows also influences the cephalad transport of airway mucus (Maxwell and Ellis, 1998; McIlwaine et al., 2017; Volpe et al., 2020). This is due to the fact that although the volume of air moving in and out of the airways during inspiration and expiration is equal, the peak flow during inspiration (PIF) is always different from that during expiration (PEF).

Early studies proposed the flow bias threshold for initiating a cephalad mucus movement in terms of PEF/PIF ratio > 1.1 (Kim et al., 1987). Later study, however, demonstrated that it is the difference between PEF and PIF rather than the PEF/PIF ratio that determines the airway mucus mobilization (Volpe et al., 2008). Although PEF-PIF $>17 \mathrm{~L} / \mathrm{min}$ is the normal threshold for initiating cephalad mucus movement, PEF-PIF $>33 \mathrm{~L} / \mathrm{min}$ is observed in vivo as a threshold to initiate mucus movement in mechanically ventilated patients and this threshold is probably more clinically relevant (Li Bassi et al., 2012). Recently, it has been updated to include three criteria for an expiratory flow bias to mobilize airway mucus cephalad movement, i.e., PEF/PIF ratio > 1.1, PEF-PIF > $17 \mathrm{~L} / \mathrm{min}, \mathrm{PEF} / \mathrm{PIF}$ ratio > 4.3 and PEF-PIF $>33 \mathrm{~L} / \mathrm{min}$ (Oliveira et al., 2019b; Volpe et al., 2008). It is worth emphasizing that this rationale does not depend on a high flow rate and can be applied even under tidal volume ventilation.

\section{Oscillating intrapulmonary airflow}

Oscillating intrapulmonary airflow can enhance mucus clearance by increasing the rate and bias of expiratory flow, ciliary beat frequency, or mucus hydration as well as by

altering the rheological properties of mucus, which can occur in both the central and the peripheral airways (Boucher, 2002; Dasgupta et al., 1998; Hansen et al., 1994; King et al., 1983; Puchelle et al., 1995; Winters et al., 2007; Winters and Yeates, 1997).

The oscillation of intrapulmonary airflow can be induced by either directly oscillating the airflow at the mouth with an oscillatory positive expiratory pressure (Osc-PEP) or vibrating the thorax using HFCWO, both of which have been proved sufficient to overcome the mucus adhesion to the airway wall in the central and peripheral airways and consequently propel the mucus up and out of the airway (Button et al., 2007; Dietl et al., 2001; Tarran et al., 2005).

\section{Physically thinning airway mucus}

As mentioned above, shear stress can physically thin airway mucus, which is also an essential pathway to promote mucus clearance (Shen et al., 2018). Apart from shear stress, nanoparticles can also be used to physically thin airway mucus. For example, it has been reported that $\mathrm{Fe}_{2} \mathrm{O}_{3}$ nanoparticles (rod-shape, $8 \mathrm{~nm}$ diameter, $100 \mathrm{~nm}$ length) can experimentally induce physical thinning of simulated asthmatic airway mucus (Fig. 6), which may be mediated by the surface interaction between the $\mathrm{Fe}_{2} \mathrm{O}_{3}$ nanoparticles and the mucin polymers (Wang et al., 2017). Our preliminary data also showed that magnetic field-driven movement of $\mathrm{Fe}_{2} \mathrm{O}_{3}$ can further decrease the viscoelasticity of the stimulated asthmatic airway mucus (data not shown). Since nanoparticles can be easily delivered into the central and peripheral airways, the phenomenon of mucus thinning induced by $\mathrm{Fe}_{2} \mathrm{O}_{3}$ nanoparticles provides another rationale for ACTs to physically thin the airway mucus and thus enhance the removal of mucus from the airways. These results suggest that novel nanotechnologies may provide alternative options for modulating airway mucus rheology for the purpose of promoting efficiency of ACTs.

\section{Airway Clearance Techniques}

Based on the above described rationales of mucus clearance, a variety of ACTs have been developed and applied in clinics including postural drainage, breathing maneuvers, conventional manual chest physiotherapy (percussion and vibration), airway oscillating PEP devices, external highfrequency chest oscillating devices, simulating cough devices such as manual hyperinflation (MHI), ventilator hyperinflation (VHI), and MI-E, as well as tracheal suctioning (Table S1).

\section{Postural drainage}

Postural drainage is an ACT that uses different body positions such as upright, side-lying, supine and prone to directly enhance airway mucus movement from the five lobes of the lung (Berney et al., 2012; Button and Button, 2013; Li Bassi et al., 2008; Safdar et al., 2005). These precise postures comprehensively utilize the anatomy of the bronchial tree, and thus facilitate the sliding of airway mucus from the periphery toward the central airways and improve ventilation and perfusion via gravity-dependent strategies. Among them, the prone position is most effective and has been strongly recommended for mechanically ventilated 

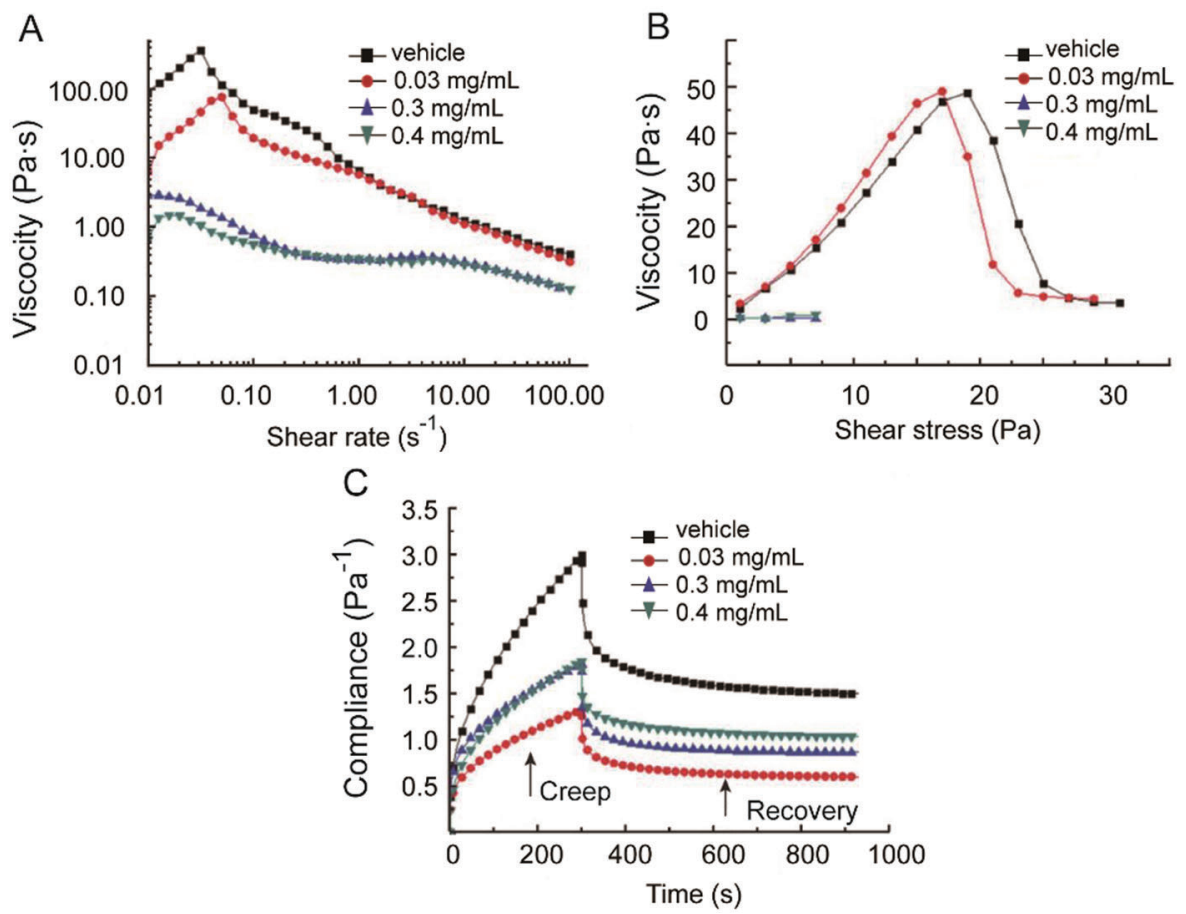

FIGURE 6. Effect of $\mathrm{Fe}_{2} \mathrm{O}_{3}$ nanoparticles on the viscoelasticity of simulated asthmatic airway mucus, adapted from (Wang et al., 2017). (A) The dynamic viscosity as a function of the shearing rate. (B) The dynamic viscosity as a function of shearing stress curve. (C) The curve of creep and recovery.

COVID-19 patients, because it promotes drainage of airway secretion, homogenizes lung perfusion, and improves ventilation mismatch (Gattinoni et al., 2020). It is also reported that although machine vibration or manual clapping does not affect severe-to-critical progression of COVID-19 patients, the prone position has been proved effective to avoid this progression via promoting mucus drainage (Wang et al., 2020).

\section{Breathing maneuvers}

Various breathing maneuvers are known to be used as helpful ACTs to clear sticky mucus out of the obstructed regions, including 3-second breath holdings, thoracic expansion exercises, mobilization by increasing expiratory flow rate or volumes, forced expiration, active cycle of breathing, and autogenic drainage (Lewis et al., 2012).

Each of these maneuvers works differently to promote mucus clearance. Specifically, the 3-second breath holdings can increase the constant time that allows the air to flow to the obstructed regions of the lung via accessory pathways as described before (Maxwell and Ellis, 1998; Mcllwaine et al., 2017). The thoracic expansion exercises use a deep, slow inspiration to increase the lung volume and thus promote ventilation to the obstructed airways via accessory pathways. Mobilization increases oxygen demand and thus increases the lung volume, which leads to ventilation behind the obstructed regions via accessory pathways (Amidei, 2012; Hodgson et al., 2014; Thomas, 2013a, b). Forced expiration such as cough and huff relies on an adequate expiratory flow rate and volume to clear the airway mucus. The active cycle of breathing combines breath holding, deep inspiration and forced expiration (Bott et al., 2009). This maneuver consists of one or two forced expirations followed by relaxed breathing. Autogenic drainage uses gently accelerated tidal volume breathing and gradually increased lung volumes to increase the expiratory flow rate and thus improve mucus clearance from peripheral to central airways (Maxwell and Ellis, 1998; McIlwaine et al., 2017). It needs to note that these breathing maneuvers may not be practical for critically ill COVID-19 patients because of their severe infirmity.

\section{Percussion and vibration}

Percussion is performed with cupped hands to clap on the thorax of the patients to generate a transient oscillation with a frequency of 3-6 Hz. Such oscillation transmits through the airways to dislodge the airway mucus from the airway wall so that the mucus can be removed out of the airways.

Similarly, the chest wall can be compressed either manually or using mechanical devices such as HFCWO to generate a transient oscillation and compression with a frequency of 3-17 Hz (McCarren et al., 2006b). This vibration is proposed to remove mucus by increasing $\mathrm{PEF}$ (about 50\%) and the expiratory flow bias or by decreasing the viscosity of mucus (Kim et al., 1987; McCarren and Alison, 2006; McCarren et al., 2006a). In addition, HFCWO utilizes an inflatable vest that is inflated with an oscillatory pressure below $25 \mathrm{cmH}_{2} \mathrm{O}$ at $5-25 \mathrm{~Hz}$. This oscillation pressure can vibrate the chest wall and generate oscillatory airflow to clear airway mucus (Darbee et al., 2005; Kendrick, 2007).

\section{Positive expiratory pressure (PEP)}

PEP helps to increase functional residual capacity and thus the tidal volume which can open obstructed airways via accessory pathways and support the airways during expiration to avoid small airway collapse (Branson, 2007; McIlwaine et al., 2015). The patients need to exhale against an expiratory resistor for 8-10 cycles with moderately increased tidal breathing to finally achieve a positive pressure of $10-25 \mathrm{cmH}_{2} \mathrm{O}$ (Demchuk and Chatburn, 2021).

Apart from 10-25 $\mathrm{cmH}_{2} \mathrm{O}$, PEP can also function with either $40-140 \mathrm{cmH}_{2} \mathrm{O}$ high pressure (Hi-PEP), oscillation 
(Osc-PEP), or $\leq 1 \quad \mathrm{cmH}_{2} \mathrm{O}$ temporary PEP (T-PEP) (Figueiredo et al., 2012). Evidence suggests that Hi-PEP helps to clear airway mucus by ventilating obstructed airways via collateral channels (Clini, 2009; Volsko et al., 2003). It is especially suitable for patients who have an airway instability during forced expiration since it avoids the premature collapse of the airways and thus allows them to exhale a greater volume than the usual forced vital capacity. Osc-PEP is characterized by breathing against intermittent expiratory resistance to induce oscillation of variable frequency and can directly dislodge the sticky mucus and also decrease mucus viscoelasticity in a frequency- and amplitude-dependent manner. T-PEP applies an expiratory pressure at $\leq 1 \mathrm{cmH}_{2} \mathrm{O}$ only for a fraction of the expiratory phase. This increase in low pressure is created through a pulsatile flow at approximately $42 \mathrm{~Hz}$ in frequency. The vibration generated by the pulsatile flow is transmitted throughout the airways to detach the mucus. Analysis suggested that T-PEP provides greater benefit to patients with emphysema or on oxygen therapy, while PEP therapy would be of more benefit for patients on mechanical ventilation (D’Abrosca et al., 2017; Nicolini et al., 2018).

\section{Intrapulmonary percussive ventilation}

Intrapulmonary percussive ventilation (IPV) provides originally high-frequency mini bursts of air at a rate of 4$10 \mathrm{~Hz}$, which creates an internal vibration in the lung and thus promotes mucus clearance. IPV is recommended for weak and fatigued patients with ineffective cough to loose secretions, which is feasible and safe in spontaneously breathing and non-intubated subjects in critical care (Berlinski, 2019; Hassan et al., 2020). Additionally, IPV can be superimposed on conventional ventilation. The potential benefits of the concomitant use of IPV with ventilation include secretion clearance, improved oxygenation, and intermittent use (Dellamonica et al., 2008).

\section{Lung hyperinflation}

Lung hyperinflation clears airway mucus by increasing inspiratory flow volume. This will recruit collapsed airways, reduce inspiratory resistance, and thus generate high expiratory flow rate bias and induce annular flow to remove airway mucus, which is predominantly used to move airway mucus from the peripheral airway to the tracheal for mechanically ventilated patients (Savian et al., 2006).

It starts with a slow deep inspiration flow to deliver a high tidal volume up to a peak pressure of $40 \mathrm{cmH}_{2} \mathrm{O}$, and follows by a 3-second breath holding, and then a fast uninterrupted expiratory flow that mimics a forced expiration (i.e., cough) (Berney and Denehy, 2002; Hodgson et al., 2007). This deep inspiration will increase tidal volume by $50 \%$ and increase peak intrabronchial pressure to 40 $\mathrm{cmH}_{2} \mathrm{O}$ (Haake et al., 1987).

Such lung hyperinflation can be realized either manually, i.e., manual hyperinflation (MHI) or mechanically by a ventilator, i.e., ventilator hyperinflation (VHI). For mechanically ventilated COVID-19 patients, VHI is more suitable than MHI, since the patients are already connected to the ventilator and maintained with PEEP, and the outcome of VHI is more reproducible than that of $\mathrm{MHI}$
(Haake et al., 1987; Volpe et al., 2020). Furthermore, it has been clarified that among different modes of VHI, the volume-controlled ventilation with inspiratory flow of $20 \mathrm{~L} / \mathrm{min}$ and pressure support achieves the best effect to remove airway mucus (Ribeiro et al., 2019).

\section{Expiratory rib cage compression}

Expiratory rib cage compression (ERCC), also known as manual chest compression, is one of the most commonly used ACTs in ventilated patients (Volpe et al., 2020). ERCC is usually applied either to assist secretion clearance from peripheral to central airways, or to remove secretion from central airways. Unlike the previously described percussion and vibration, ERRC is applied with a steady force that gradually increases from gentle to strong intensity to prolong exhalation after the onset of the expiratory phase, which is used to remove the secretions from distal airways. To remove the secretions from proximal airways, ERRC is applied with hard compression to increase PEF and synchronized with the onset of expiration (Borges et al., 2017; Guimaraes et al., 2013; Martí et al., 2013).

Positive end-expiratory pressure-zero end expiratory pressure Positive end-expiratory pressure-zero end expiratory pressure (PEEP-ZEEP) consists of increasing PEEP to $15 \mathrm{cmH}_{2} \mathrm{O}$ during 5 cycles with peak inspiratory pressure limited to $40 \mathrm{cmH}_{2} \mathrm{O}$, followed by an abrupt reduction of PEEP to $0 \mathrm{cmH}_{2} \mathrm{O}$. By increasing the pressure change at the onset of the expiratory phase, this technique increases the PEF and, consequently, the expiratory flow bias, especially in the volume controlled mode (Amaral et al., 2020; Oliveira et al., 2019a; Volpe et al., 2020). Although both ERCC and PEEPZEEP are responsible for increasing the expiratory flow bias, the latter is more potent in this aspect $(7 \mathrm{~L} / \mathrm{min} v s$. $49 \mathrm{~L} / \mathrm{min}$ ) (Oliveira et al., 2019a).

\section{Mechanical insufflation-exsufflation}

Mechanical insufflation-exsufflation (MI-E) is the most recently developed technique for mechanically ventilated patients, which delivers a positive inspiratory pressure to the patient to generate a deep inspiration (insufflation) and immediately $(10 \mathrm{~ms})$ followed by a negative expiratory pressure generating a deep expiration (exsufflation). In this way, a PEF greater than that induced by coughing can be achieved to remove airway mucus more effectively. In addition, the rapid switch from positive to negative pressure stimulates the bias flow. The advantage of MI-E is that it induces negative pressure throughout central and peripheral airways, suggesting that airway mucus in all generations of the airways can be removed (Ferreira de Camillis et al., 2018; Terzi et al., 2018).

\section{Tracheal suctioning}

Tracheal suctioning can clear sticky mucus from the trachea and the lower airways, which can be performed via an inline closed system or an open system (Dodek et al., 2004). Although tracheal suctioning should not be used as a routine ACT for non-intubated patients, it is recommended for the mechanically ventilated COVID-19 patients with 
suction catheters of an in-line closed system, considering the risk of generating virus aerosol with an open system.

\section{Airway Clearance Algorithm}

Although various ACTs can effectively remove airway mucus, there is still no gold standard of clinical ACT practice for critically ill COVID-19 patients. One of the reasons is that one ACT may function differently to different patients depending on the specific pathological process and respiratory mechanics of each individual. Additionally, it may not be possible to compare all the ACTs and affirm the one with superiority. Lastly, each of the critically ill COVID-19 patients can present different respiratory conditions at a different stage of the disease, and thus may need different ACTs over the course of treatment (Battaglini et al., 2020; Lazzeri et al., 2020).

Nevertheless, for critically ill COVID-19 patients, passive ACTs such as postural drainage, percussion, vibration, oscillation, hyperinflation and MI-E may be more suitable than active ACTs such as breathing maneuvers and PEP, because of their physical frailty (Homnick, 2007; van der Schans et al., 1999; Wilson et al., 2019). In addition, the carers in close range of critically ill COVID-19 patients may be endangered by exposure to the virus aerosolized into the environment (Patel et al., 2020; Zayas et al., 2005). Considering this risk, mechanical devices such as HFCWO, VHI, and MI-E are more suitable than manual techniques to be used for the management of airway mucus of critically ill COVID-19 patients, despite that the manual techniques are also effective in mucus clearance. In practice, the treatment approach should be decided based on carefully evaluating the conditions of the patient and the features of available ACTs following the algorithm as shown in Fig. 7 (Chatburn, 2007; Konrad et al., 1994; Sivasothy et al., 2001).

Furthermore, it has been recommended to consider different internal rationales and application conditions of all the ACTs, and thus adapt a combinational therapeutic strategy of using several ACTs during the management of airway mucus (Ramos et al., 2015). For example, although HFCWO is effective to mobilize secretions from the small airways, it does not provide ventilation behind obstructed airways. As a consequence, HFCWO can lead to $10 \%-50 \%$ reduction of the end-expiratory volume, which may close small airways and worsen pulmonary function (Dosman et al., 2003; Jones et al., 1995). However, this event can be avoided by 3 -second breathing holds or deep inspiration prior to HFCWO. In addition, HFCWO can be used to mobilize mucus from the small airway to the proximal airways, and then tracheal suctioning can be further used to clear them out from the proximal airway. And when tracheal suctioning does not provide adequate mucus clearance in mechanically ventilated patients, it can be augmented by PEEP-DEEP and MI-E. Compared to tracheal suctioning that is routinely performed for invasive ventilation, MI-E may be more suitable for eliminating airway mucus in ventilated COVID-19 patients due to its advantages in convenience and comfortability in use (Garstang et al., 2000; Sancho et al., 2003). In fact, MI-E is recommended by the Canadian Thoracic Society to be added to or replace the tracheal suctioning (McKim et al., 2011).

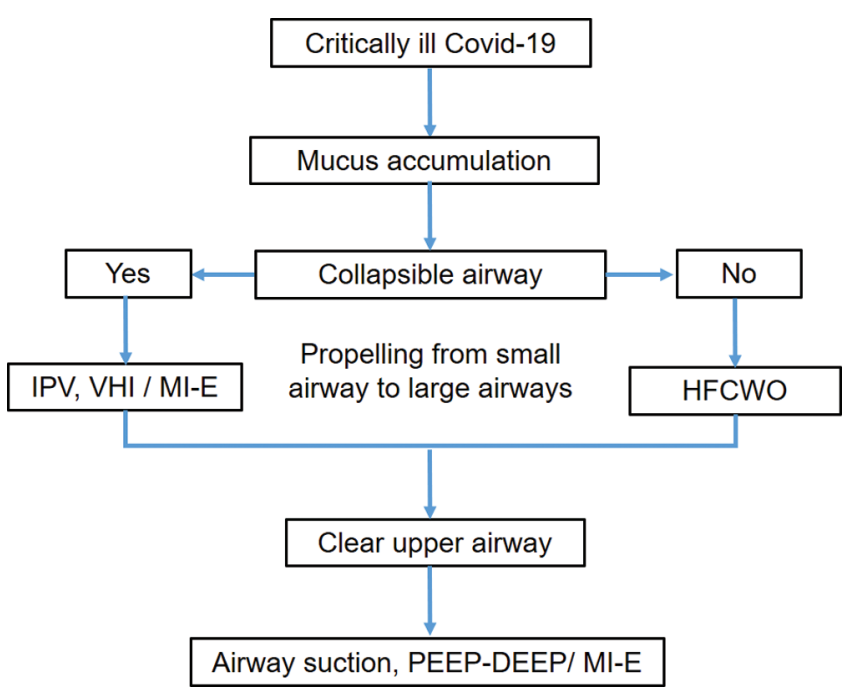

FIGURE 7. Airway clearance algorithm for critically ill COVID-19 patients, adapted from (Chatburn, 2007; Konrad et al., 1994a; Sivasothy et al., 2001).

Therefore, for critically ill COVID-19 patients, some ACTs such as HFCWO, MHI combined with 3-second breathing hold or IPV may be used together to dislodge the mucus in smaller airways and subsequently move the mucus to the larger airways. Then other ACTs such as tracheal suctioning and/or MI-E should be used to clear these mobilized secretions (Stiller, 2000, 2013; Volsko, 2013).

\section{Limitations of Current ACTs and Future Directions}

So far, the underlying mechanisms of airway mucus accumulation in COVID-19 are still unclear, which includes but is not limited to the unknown changes of hydration, biochemical constituents and correlated rheological features in the airway mucus of the patients. The other limitation is that although various ACTs have been used for critically ill COVID-19 patients, there are still not established criteria for determining what ACTs are the most suitable and when they should be used because there is not sufficient evidence to compare and evaluate the currently available ACTs for their efficacy and safety in clinical usage. Therefore, it is urgent for future studies to clarify the changes of specific types of mucins and the correlated rheological properties of airway mucus in COVID-19 patients. It is also necessary to explore new techniques such as abdominal electrical stimulation, nanotechnology, and artificial intelligence for their potential applications in airway mucus clearance, which may be key to optimize the use of existing ACTs as well as develop new ACTs for ultimate control of airway mucus clearance in COVID-19 (Spinou, 2018; Volpe et al., 2020).

\section{Conclusion}

COVID-19 is an emerging infectious respiratory disease that has not been completely delineated, and clearance of excessive mucus accumulation in the airways remains one of the biggest challenges in the treatment of critically ill COVID-19 patients due to lack of knowledge of the mucus changes in the disease and corresponding techniques for optimal mucus clearance. In this review, we outline the 
chemical and rheological features of airway mucus in physiopathological conditions especially in relation to COVID-19 and the currently available ACTs, as well as highlight the essential roles of mechanical forces and their interactions with airway mucus. A clear understanding of these aspects will provide novel insights for new therapeutic approaches or strategies for the airway mucus management of critically ill COVID-19 patients. Based on comprehensive considerations of all these principles and factors, an optimized strategy may be developed to meet the specific requirements for clearing airway mucus in critically ill COVID-19 patients.

Author Contributions: M. Luo and L. Deng conceived and designed the study. M. Luo wrote the manuscript. K. Ni, Y. Sun, J. Guo, and K. Wen collected some data for this manuscript. L. Deng revised the manuscript.

Funding Statement: This work was partially supported by the Key Program of the NSF of China [No. 11532003], the NSF of China [Nos. 12072048, 31670950], the Science and Technology Innovation Leading Plan of High Tech Industry in Hunan Province [2020SK2018], and the Applied Basic Research Project of Changzhou [No. CJ20179039].

Conflicts of Interest: The authors declare that they have no conflicts of interest to report regarding the present study.

\section{References}

Amaral BLR, de Figueiredo AB, Lorena DM, Oliveira ACO, Carvalho NC, Volpe MS (2020). Effects of ventilation mode and manual chest compression on flow bias during the positive end- and zero end-expiratory pressure manoeuvre in mechanically ventilated patients: A randomised crossover trial. Physiotherapy 106: 145-153. DOI 10.1016/j.physio.2018.12.007.

Ambrosino N, Clini EM (2015). Response to pulmonary rehabilitation: Toward personalised programmes? European Respiratory Journal 46: 1538-1540. DOI 10.1183/13993003.01125-2015.

Amidei C (2012). Mobilisation in critical care: A concept analysis. Intensive and Critical Care Nursing 28: 73-81. DOI 10.1016/j.iccn.2011.12.006.

Anderson WH, Coakley RD, Button B, Henderson AG, Zeman KL et al. (2015). The relationship of mucus concentration (hydration) to mucus osmotic pressure and transport in chronic bronchitis. American Journal of Respiratory and Critical Care Medicine 192: 182-190. DOI 10.1164/ rccm.201412-2230OC.

App EM, Kieselmann R, Reinhardt D, Lindemann H, Dasgupta B et al. (1998). Sputum rheology changes in cystic fibrosis lung disease following two different types of physiotherapy: Flutter vs. autogenic drainage. Chest 114: 171-177. DOI 10.1378/chest.114.1.171.

Baden LR, Rubin EJ (2020). COVID-19-The search for effective therapy. New England Journal of Medicine 382: 1851-1852. DOI 10.1056/NEJMe2005477.

Balsamo R, Lanata L, Egan CG (2010). Mucoactive drugs. European Respiratory Review 19: 127-133. DOI 10.1183/09059180.00003510.

Bansil R, Stanley E, Lamont JT (1995). Mucin biophysics. Annual Review of Physiology 57: 635-657. DOI 10.1146/annurev. ph.57.030195.003223.

Battaglini D, Robba C, Caiffa S, Ball L, Brunetti I et al. (2020). Chest physiotherapy: An important adjuvant in critically ill mechanically ventilated patients with COVID-19. Respiratory Physiology \& Neurobiology 282: 103529. DOI 10.1016/j.resp.2020.103529.

Belli S, Prince I, Savio G, Paracchini E, Cattaneo D et al. (2021). Airway clearance techniques: The right choice for the right patient. Frontiers in Medicine 8: 544826. DOI 10.3389/ fmed.2021.544826.

Berlinski A (2019). Be aware of intrapulmonary percussive ventilation. Respiratory Care 64: 612-613. DOI 10.4187/ respcare.07049.

Berney S, Denehy L (2002). A comparison of the effects of manual and ventilator hyperinflation on static lung compliance and sputum production in intubated and ventilated intensive care patients. Physiotherapy Research International 7: 100108. DOI 10.1002/(ISSN)1471-2865.

Berney S, Haines K, Denehy L (2012). Physiotherapy in critical care in Australia. Cardiopulmonary Physical Therapy Journal 23: 19-25. DOI 10.1097/01823246-201223010-00004.

Borges LF, Saraiva MS, Saraiva MAS, Macagnan FE, Kessler A (2017). Expiratory rib cage compression in mechanically ventilated adults: Systematic review with meta-analysis. Revista Brasileira de Terapia Intensiva 29: 96-104. DOI 10.5935/ 0103-507X.20170014.

Bose M, Mitra B, Mukherjee P (2021). Mucin signature as a potential tool to predict susceptibility to COVID-19. Physiological Reports 9: e14701.

Bott J, Blumenthal S, Buxton M, Ellum S, Falconer C et al. (2009). Guidelines for the physiotherapy management of the adult, medical, spontaneously breathing patient. Thorax 64: i1i52. DOI 10.1136/thx.2008.110726.

Boucher RC (2002). An overview of the pathogenesis of cystic fibrosis lung disease. Advanced Drug Delivery Reviews 54: 1359-1371. DOI 10.1016/S0169-409X(02)00144-8.

Branson RD (2007). Secretion management in the mechanically ventilated patient. Respiratory Care 52: 1328-1347.

Brewster DJ, Chrimes NC, Do TB, Frser K, Groombridge CJ et al. (2020). Consensus statement safe airway society principles of airway. Medical Journal of Australia 214: 46. DOI 10.5694/mja2.50889.

Brosnahan SB, Jonkman AH, Kugler MC, Munger JS, Kaufman DA (2020). COVID-19 and respiratory system disorders. Arteriosclerosis, Thrombosis, and Vascular Biology 40: 2586-2597. DOI 10.1161/ATVBAHA.120.314515.

Button B, Anderson WH, Boucher RC (2016). Mucus hyperconcentration as a unifying aspect of the chronic bronchitic phenotype. Annals of the American Thoracic Society 13 Suppl 2: S156-S162.

Button B, Cai LH, Ehre C, Kesimer M, Hill DB et al. (2012). A periciliary brush promotes the lung health by separating the mucus layer from airway epithelia. Science 337: 937941. DOI 10.1126/science.1223012.

Button B, Picher M, Boucher RC (2007). Differential effects of cyclic and constant stress on ATP release and mucociliary transport by human airway epithelia. Journal of Physiology 580: 577592. DOI 10.1113/jphysiol.2006.126086.

Button BM, Button B (2013). Structure and function of the mucus clearance system of the lung. Cold Spring Harbor Perspectives in Medicine 3: a009720. DOI 10.1101/cshperspect.a009720.

Cao B, Wang Y, Wen D, Liu W, Wang J et al. (2020). A trial of lopinavir-ritonavir in adults hospitalized with severe COVID-19. New England Journal of Medicine 382: 17871799. DOI 10.1056/NEJMoa2001282. 
Cascella M, Rajnik M, Cuomo A, Dulebohn SC, di Napoli R (2021). Features, evaluation and treatment coronavirus (COVID-19). In: StatPearls (Treasure Island FL: StatPearls Publishing LLC.). Florida.

Castelli V, Cimini A, Ferri C (2020). Cytokine storm in COVID-19: When you come out of the storm, you won't be the same person who walked in. Frontiers in Immunology 11: 760. DOI 10.3389/fimmu.2020.02132.

Castro AAM, Calil SR, Freitas SA, Oliveira AB, Porto EF (2013). Chest physiotherapy effectiveness to reduce hospitalization and mechanical ventilation length of stay, pulmonary infection rate and mortality in ICU patients. Respiratory Medicine 107: 68-74. DOI 10.1016/j.rmed.2012.09.016.

Cerveri I, Brusasco V (2010). Revisited role for mucus hypersecretion in the pathogenesis of COPD. European Respiratory Review 19: 109-112. DOI 10.1183/09059180.00002710.

Cetti EJ, Moore AJ, Geddes DM (2006). Collateral ventilation. Thorax 61: 371-373. DOI 10.1136/thx.2006.060509.

Chatburn RL (2007). High-frequency assisted airway clearance. Respiratory Care 52: 1224-1237.

Chatterjee M, van Putten JPM, Strijbis K, Garsin DA (2020). Defensive properties of mucin glycoproteins during respiratory infections-Relevance for SARS-CoV-2. mBio 11: e02374-20. DOI 10.1128/mBio.02374-20.

Chen Z, Zhong M, Jiang L, Chen N, Tu S et al. (2020). Effects of the lower airway secretions on airway opening pressures and suction pressures in critically ill COVID-19 patients: A computational simulation. Annals of Biomedical Engineering 48: 3003-3013. DOI 10.1007/s10439-020-02648-0.

Chen Z, Zhong M, Luo Y, Deng L, Hu Z et al. (2019a). Determination of rheology and surface tension of airway surface liquid: A review of clinical relevance and measurement techniques. Respiratory Research 20: 3. DOI 10.1186/s12931-019-1229-1.

Chen ZG, Wang ZN, Yan Y, Liu J, He TT et al. (2019b). Upregulation of cell-surface mucin MUC15 in human nasal epithelial cells upon influenza A virus infection. BMC Infectious Diseases 19: 210. DOI 10.1186/s12879-019-4213-y.

Chilvers MA, McKean M, Rutman A, Myint BS, Silverman M et al. (2001). The effects of coronavirus on human nasal ciliated respiratory epithelium. European Respiratory Journal 18: 965-970. DOI 10.1183/09031936.01.00093001.

Clini E (2009). Positive expiratory pressure techniques in respiratory patients: Old evidence and new insights. Breathe 6: 153-159. DOI 10.1183/18106838.0602.153.

Cone RA (2009). Barrier properties of mucus. Advanced Drug Delivery Reviews 61: 75-85. DOI 10.1016/j.addr.2008.09.008.

Cook TM, El-Boghdadly K, McGuire B, McNarry AF, Patel A et al. (2020). Consensus guidelines for managing the airway in patients with COVID-19. Anaesthesia 75: 785-799. DOI 10.1111/anae.15054.

Curran DR, Cohn L (2010). Advances in mucous cell metaplasia: A plug for mucus as a therapeutic focus in chronic airway disease. American Journal of Respiratory Cell and Molecular Biology 42: 268-275. DOI 10.1165/rcmb.2009-0151TR.

D’Abrosca F, Garabelli B, Savio G, Barison A, Appendini L et al. (2017). Comparing airways clearance techniques in chronic obstructive pulmonary disease and bronchiectasis: Positive expiratory pressure or temporary positive expiratory pressure? A retrospective study. Brazilian Journal of Physical Therapy 21: 15-23. DOI 10.1016/j.bjpt.2016.12.001.
Darbee JC, Kanga JF, Ohtake PJ (2005). Physiologic evidence for high-frequency chest wall oscillation and positive expiratory pressure breathing in hospitalized subjects with cystic fibrosis. Physical Therapy 85: 1278-1289. DOI 10.1093/ptj/85.12.1278.

Dasgupta B, Brown NE, King M (1998). Effects of sputum oscillations and rhDNase in vitro: A combined approach to treat cystic fibrosis lung disease. Pediatric Pulmonology 26: 250-255. DOI 10.1002/(ISSN)1099-0496.

Dellamonica J, Louis B, Lyazidi A, Vargas F, Brochard L (2008). Intrapulmonary percussive ventilation superimposed on conventional ventilation: Bench study of humidity and ventilator behaviour. Intensive Care Medicine 34: 20352043. DOI 10.1007/s00134-008-1190-9.

Demchuk AM, Chatburn RL (2021). Performance characteristics of positive expiratory pressure devices. Respiratory Care 66: 482-493. DOI 10.4187/respcare.08150.

Denehy L, Berney S (2013). Physiotherapy in the intensive care unit. Physical Therapy Reviews 11: 49-56. DOI 10.1179/ 108331906X98921.

Denneny E, Sahota J, Beatson R, Thornton D, Burchell J et al. (2020). Mucins and their receptors in chronic lung disease. Clinical \& Translational Immunology 9: A7560. DOI 10.1002/cti2.1120.

Dhanisha SS, Guruvayoorappan C, Drishya S, Abeesh P (2018). Mucins: Structural diversity, biosynthesis, its role in pathogenesis and as possible therapeutic targets. Critical Reviews in Oncology/ Hematology 122: 98-122. DOI 10.1016/j.critrevonc.2017.12.006.

Dickey BF (2018). What it takes for a cough to expel mucus from the airway. Proceedings of the National Academy of Sciences of the United States of America 115: 12340-12342. DOI 10.1073/ pnas.1817484115.

Dietl P, Haller T, Mair N, Frick M (2001). Mechanisms of surfactant exocytosis in alveolar type ii cells in vitro and in vivo. Physiology 16: 239-243. DOI 10.1152/physiologyonline.2001.16.5.239.

Dodek P, Keenan S, Cook D, Heyland D, Jacka M et al. (2004). Evidence-based clinical practice guideline for the prevention of ventilator-associated pneumonia. Annals of Internal Medicine 141: 305-313. DOI 10.7326/0003-4819141-4-200408170-00011.

Dosman CF, Zuberbuhler PC, Tabak JI, Jones RL (2003). Effects of positive end-expiratory pressure on oscillated volume during high frequency chest compression in children with cystic fibrosis. Canadian Respiratory Journal 10: 94-98. DOI 10.1155/2003/792917.

Dunican EM, Elicker BM, Gierada DS, Nagle SK, Schiebler ML et al. (2018). Mucus plugs in patients with asthma linked to eosinophilia and airflow obstruction. Journal of clinical investigation 128: 997-1009. DOI 10.1172/JCI95693.

Essaidi-Laziosi M, Brito F, Benaoudia S, Royston L, Cagno V et al. (2018). Propagation of respiratory viruses in human airway epithelia reveals persistent virus-specific signatures. Journal of Allergy and Clinical Immunology 141: 2074-2084. DOI 10.1016/j.jaci.2017.07.018.

Fahy JV, Dickey BF (2010). Airway mucus function and dysfunction. New England Journal of Medicine 363: 2233-2247. DOI 10.1056/NEJMra0910061.

Fan E, Del Sorbo L, Goligher EC, Hodgson CL, Munshi L et al. (2017). An official american thoracic society/european society of intensive care medicine/society of critical care medicine clinical practice guideline: Mechanical ventilation in adult patients with acute respiratory distress syndrome. 
American Journal of Respiratory and Critical Care Medicine 195: 1253-1263. DOI 10.1164/rccm.201703-0548ST.

Fang Y, Liu H, Huang H, Li H, Saqi A, Qiang L, Que J (2020). Distinct stem/progenitor cells proliferate to regenerate the trachea, intrapulmonary airways and alveoli in COVID-19 patients. Cell Research 30: 705-707. DOI 10.1038/s41422-020-0367-9.

Ferreira de Camillis ML, Savi A, Goulart Rosa R, Figueiredo M, Wickert $\mathrm{R}$ et al. (2018). Effects of mechanical insufflationexsufflation on airway mucus clearance among mechanically ventilated ICU subjects. Respiratory Care 63: 1471-1477. DOI 10.4187/respcare.06253.

Figueiredo PH, Zin WA, Guimaraes FS (2012). Flutter valve improves respiratory mechanics and sputum production in patients with bronchiectasis. Physiotherapy Research International 17: 12-20. DOI 10.1002/pri.507.

Fink JB (2007). Forced expiratory technique, directed cough, and autogenic drainage. Respiratory Care 52: 1210-1221.

Ganesan S, Comstock AT, Sajjan US (2013). Barrier function of airway tract epithelium. Tissue Barriers 1: e24997. DOI 10.4161/tisb.24997.

Garstang SV, Kirshblum SC, Wood KE (2016). Patient preference for in-exsufflation for secretion management with spinal cord injury. Journal of Spinal Cord Medicine 23: 80-85. DOI 10.1080/10790268.2000.11753511.

Gattinoni L, Coppola S, Cressoni M, Busana M, Rossi S et al. (2020). COVID-19 does not lead to a "typical" acute respiratory distress syndrome. American Journal of Respiratory and Critical Care Medicine 201: 1299-1300. DOI 10.1164/ rccm.202003-0817LE.

Gosselink R, Bott J, Johnson M, Dean E, Nava S et al. (2008). Physiotherapy for adult patients with critical illness: Recommendations of the European Respiratory Society and European Society of Intensive Care Medicine Task Force on Physiotherapy for Critically Ill Patients. Intensive Care Medicine 34: 1188-1199. DOI 10.1007/s00134-008-1026-7.

Guan W, Ni Z, Hu Y, Liang W, Ou C et al. (2020). Clinical characteristics of coronavirus disease 2019 in China. New England Journal of Medicine 382: 1708-1720. DOI 10.1056/ NEJMoa2002032.

Guimaraes FS, Lopes AJ, Constantino SS, Lima JC, Canuto P et al. (2014). Expiratory rib cage compression in mechanically ventilated subjects: A randomized crossover trial. Respiratory Care 59: 678-685. DOI 10.4187/respcare.02587.

Haake R, Schlichttg R, Ulstad DR, Henschen RR (1987). Barotrauma: Pathophysiology, risk factors, and prevention. Chest 91: 608613. DOI 10.1378/chest.91.4.608.

Hadjadj J, Yatim N, Barnabei L, Corneau A, Boussier J et al. (2020). Impaired type I interferon activity and inflammatory responses in severe COVID-19 patients. Science 369: 718724. DOI 10.1126/science.abc6027.

Hansen LG, Warwick WJ, Hansen KL (1994). Mucus transport mechanisms in relation to the effect of high frequency chest compression (HFCC) on mucus clearance. Pediatric Pulmonology 17: 113-118. DOI 10.1002/(ISSN)1099-0496.

Hassan A, Milross M, Lai W, Shetty D, Alison J et al. (2021). Feasibility and safety of intrapulmonary percussive ventilation in spontaneously breathing, non-ventilated patients in critical care: A retrospective pilot study. Journal of the Intensive Care Society 22: 111-119. DOI 10.1177/1751143720909704.

Hattrup CL, Gendler SJ (2008). Structure and function of the cell surface (tethered) mucins. Annual Review of Physiology 70: 431-457. DOI 10.1146/annurev.physiol.70.113006.100659.
Hodgson C, Ntoumenopoulos G, Dawson H, Paratz J (2007). The Mapleson C circuit clears more secretions than the Laerdal circuit during manual hyperinflation in mechanicallyventilated patients: A randomised cross-over trial. Australian Journal of Physiotherapy 53: 33-38. DOI 10.1016/S0004-9514(07)70059-4.

Hodgson CL, Stiller K, Needham DM, Tipping CJ, Harrold M et al. (2014). Expert consensus and recommendations on safety criteria for active mobilization of mechanically ventilated critically ill adults. Critical Care (London, England) 18: 654. DOI 10.1186/s13054-014-0658-y.

Hogg JC (2004). Pathophysiology of airflow limitation in chronic obstructive pulmonary disease. Lancet 364: 709-721. DOI 10.1016/S0140-6736(04)16900-6.

Hollandl AE, Buttonl BM (2006). Is there a role for airway clearance techniques in chronic obstructive pulmonary disease? Chronic Respiratory Disease 3: 83-91. DOI 10.1191/ 1479972306cd097rs.

Homnick DN (2007). Making airway clearance successful. Paediatric Respiratory Reviews 8: 40-45. DOI 10.1016/j.prrv.2007.02.002.

Huang C, Wang Y, Li X, Ren L, Zhao J et al. (2020). Clinical features of patients infected with 2019 novel coronavirus in Wuhan, China. Lancet 395: 497-506. DOI 10.1016/S0140-6736(20) 30183-5.

Iyer GR, Samajder S, Zubeda S, DSN S, Mali V et al. (2020). Infectivity and progression of COVID-19 based on selected host candidate gene variants. Frontiers in Genetics 11: 1. DOI 10.3389/fgene.2020.00861.

Jones RL, Lester RT, Brown NE (1995). Effects of high frequency chest compression on respiratory system mechanics in normal subjects and cystic fibrosis patients. Canadian Respiratory Journal 2: 40-46. DOI 10.1155/1995/656409.

Kaminsky DA, Chapman DG (2020). Asthma and lung mechanics. Comprehensive Physiology 10: 975-1007.

Kendrick AH (2007). Airway clearance techniques in cystic fibrosis: Physiology, devices and the future. Journal of the Royal Society of Medicine 100 Suppl 47: 3-23.

Khan MA, Khan ZA, Charles M, Pratap P, Naeem A et al. (2021). Cytokine storm and mucus hypersecretion in COVID-19: Review of mechanisms. Journal of Inflammation Research 14: 175-189. DOI 10.2147/JIR.S271292.

Kim CS, Greene MA, Sankaran S, Sackner MA (1986a). Mucus transport in the airways by two-phase gas-liquid flow mechanism: continuous flow model. Journal of Applied Physiology 60: 908-917. DOI 10.1152/jappl.1986.60.3.908.

Kim CS, Iglesias AJ, Sackner MA (1987). Mucus clearance by twophase gas-liquid flow mechanism: Asymmetric periodic flow model. Journal of Applied Physiology 62: 959-971. DOI 10.1152/jappl.1987.62.3.959.

Kim CS, Rodriguez CR, Eldridge MA, Sackner MA (1986b). Criteria for mucus transport in the airways by two-phase gas-liquid flow mechanism. Journal of Applied Physiology 60: 901907. DOI 10.1152/jappl.1986.60.3.901.

Kim WD (1997). Lung mucus: A clinician's view. European Respiratory Journal 10: 1914-1917. DOI 10.1183/09031936.97.10081914.

King M, Phillips DM, Gross D, Vartian V, Chang HK et al. (1983). Enhanced tracheal mucus clearance with high frequency chest wall compression. American Review of Respiratory Disease 128: 511-515. DOI 10.1164/arrd.1983.128.3.511.

Konrad F, Schreiber T, Brecht-Kraus D, Georgieff M (1994). Mucociliary transport in ICU patients. Chest 105: 237-241. DOI 10.1378/chest.105.1.237. 
Kuek LE, Lee RJ (2020). First contact: the role of respiratory cilia in host-pathogen interactions in the airways. American Journal of Physiology-Lung Cellular and Molecular Physiology 319: L603-L619. DOI 10.1152/ajplung.00283.2020.

Lai SK, Wang YY, Wirtz D, Hanes J (2009). Micro- and macrorheology of mucus. Advanced Drug Delivery Reviews 61: 86-100. DOI 10.1016/j.addr.2008.09.012.

Lazzeri M, Lanza A, Bellini R, Bellofiore A, Cecchetto S et al. (2020). Respiratory physiotherapy in patients with COVID-19 infection in acute setting: A Position Paper of the Italian Association of Respiratory Physiotherapists (ARIR). Monaldi Archives for Chest Disease 90: 1285. DOI 10.4081/ monaldi.2020.1285.

Lee IT, Nakayama T, Wu C, Goltsev Y, Jiang S et al. (2020). ACE2 localizes to the respiratory cilia and is not increased by ACE inhibitors or ARBs. Nature Communications 11: 265. DOI 10.1038/s41467-020-19145-6.

Leith DE (1968). Cough. Physical Therapy 48: 439-447. DOI 10.1093/ $\mathrm{ptj} / 48.5 .439$.

Leng L, Cao R, Ma J, Mou D, Zhu Y et al. (2020). Pathological features of COVID-19-associated lung injury: A preliminary proteomics report based on clinical samples. Signal Transduction and Targeted Therapy 5: 240. DOI 10.1038/s41392-020-00355-9.

Lester MK, Flume PA (2009). Airway-clearance therapy guidelines and implementation. Respiratory Care 54: 733-753. DOI $10.4187 / 002013209790983205$.

Lewis LK, Williams MT, Olds TS (2012). The active cycle of breathing technique: A systematic review and metaanalysis. Respiratory Medicine 106: 155-172. DOI 10.1016/ j.rmed.2011.10.014.

Li Bassi G, Saucedo L, Marti J-D, Rigol M, Esperatti M et al. (2012). Effects of duty cycle and positive end-expiratory pressure on mucus clearance during mechanical ventilation* ${ }^{*}$ Critical Care Medicine 40: 895-902. DOI 10.1097/CCM.0b013e318236efb5.

Li Bassi G, Zanella A, Cressoni M, Stylianou M, Kolobow T (2008). Following tracheal intubation, mucus flow is reversed in the semirecumbent position: Pssible role in the pathogenesis of ventilator-associated pneumonia. Critical Care Medicine 36: 518-525. DOI 10.1097/01.CCM.0000299741.32078.E9.

Lillehoj EP, Kato K, Lu W, Kim KC (2013). Cellular and molecular biology of airway mucins. International Review of Cell and Molecular Biology 303: 139-202. DOI 10.1016/B978-0-12407697-6.00004-0.

Liu Q, Wang RS, Qu GQ, Wang YY, Liu P et al. (2020a). Gross examination report of a COVID-19 death autopsy. Fa Yi Xue Za Zhi 36: 21-23.

Liu Y, Lv J, Liu J, Li M, Xie J et al. (2020b). Mucus production stimulated by IFN-AhR signaling triggers hypoxia of COVID-19. Cell Research 30: 1078-1087. DOI 10.1038/s41422-020-00435-z.

Loreng TD, Smith EF (2017). The central apparatus of cilia and eukaryotic flagella. Cold Spring Harbor Perspectives in Biology 9: a028118. DOI 10.1101/cshperspect.a028118.

Lorenzi G, Bohm GM, Guimaraes ET, Vaz MA, King M et al. (1992). Correlation between rheologic properties and in vitro ciliary transport of rat nasal mucus. Biorheology 29: 433-440. DOI 10.3233/BIR-1992-29406.

Lu W, Liu X, Wang T, Liu F, Zhu A et al. (2021). Elevated MUC1 and MUC5AC mucin protein levels in airway mucus of critical ill COVID-19 patients. Journal of Medical Virology 93: 582-584. DOI 10.1002/jmv.26406.
Macchione M, King M, Lorenzi-Filho G, Guimarães ET, Zin WA et al. (1995). Rheological determinants of mucociliary transport in the nose of the rat. Respiration Physiology 99: 165-172. DOI 10.1016/0034-5687(94)00080-J.

Majima Y, Jin CS, Takeuchi K, Hamaguchi Y, Sakakura Y et al. (1991). Rheological properties of middle ear mucus in relation to goblet cell population in cat. Acta OtoLaryngologica Supplementum 483: 11-16. DOI 10.3109/ 00016489109127696.

Martí JD, Li Bassi G, Rigol M, Saucedo L, Ranzani OT et al. (2013). Effects of manual rib cage compressions on expiratory flow and mucus clearance during mechanical ventilation. Critical Care Medicine 41: 850-856. DOI 10.1097/ CCM.0b013e3182711b52.

Maxwell L, Ellis E (1998). Secretion clearance by manual hyperinflation: Possible mechanisms. Physiotherapy Theory and Practice 14: 189-197. DOI 10.3109/09593989809057165.

McAuley JL, Corcilius L, Tan HX, Payne RJ, McGuckin MA et al. (2017). The cell surface mucin MUC1 limits the severity of influenza A virus infection. Mucosal Immunology 10: 15811593. DOI 10.1038/mi.2017.16.

McAuley JL, Gilbertson BP, Trifkovic S, Brown LE, McKimmBreschkin JL (2019). Influenza virus neuraminidase structure and functions. Frontiers in Microbiology 10: 971. DOI 10.3389/fmicb.2019.00039.

McCarren B, Alison JA (2006). Physiological effects of vibration in subjects with cystic fibrosis. European Respiratory Journal 27: 1204-1209. DOI 10.1183/09031936.06.00083605.

McCarren B, Alison JA, Herbert RD (2006a). Manual vibration increases expiratory flow rate via increased intrapleural pressure in healthy adults: An experimental study. Australian Journal of Physiotherapy 52: 267-271. DOI 10.1016/S0004-9514(06)70006-X.

McCarren B, Alison JA, Herbert RD (2006b). Vibration and its effect on the respiratory system. Australian Journal of Physiotherapy 52: 39-43. DOI 10.1016/S0004-9514(06)70060-5.

Mcllwaine M, Bradley J, Elborn JS, Moran F (2017). Personalising airway clearance in chronic lung disease. European Respiratory Review: An Official Journal of the European Respiratory Society 26: 160086. DOI 10.1183/16000617.0086-2016.

McIlwaine M, Button B, Dwan K (2015). Positive expiratory pressure physiotherapy for airway clearance in people with cystic fibrosis. Cochrane Database of Systematic Reviews 19: 16. DOI 10.1002/14651858.CD003147.pub4.

McKim DA, Road J, Avendano M, Abdool S, Cote F et al. (2011). Home mechanical ventilation: A Canadian Thoracic Society clinical practice guideline. Canadian Respiratory Journal 18: 197-215. DOI 10.1155/2011/139769.

Murthy S, Gomersall CD, Fowler RA (2020). Care for critically ill patients with COVID-19. JAMA 323: 1499-1500. DOI 10.1001/jama.2020.3633.

Nicolini A, Mascardi V, Grecchi B, Ferrari-Bravo M, Banfi P et al. (2018). Comparison of effectiveness of temporary positive expiratory pressure versus oscillatory positive expiratory pressure in severe COPD patients. Clinical Respiratory Journal 12: 1274-1282. DOI 10.1111/crj.12661.

Oberwaldner B (2000). Physiotherapy for airway clearance in paediatrics. European Respiratory Journal 15: 196-204. DOI 10.1183/09031936.00.15119600.

Oliveira ACO, Lorena DM, Gomes LC, Amaral BLR, Volpe MS (2019a). Effects of manual chest compression on expiratory flow bias during the positive end-expiratory pressure-zero 
end-expiratory pressure maneuver in patients on mechanical ventilation. Jornal Brasileiro de Pneumologia 45: 1328. DOI 10.1590/1806-3713/e20180058.

Oliveira ACO, Lorena DM, Gomes LC, Amaral BLR, Volpe MS (2019b). Effects of manual chest compression on expiratory flow bias during the positive end-expiratory pressure-zero end-expiratory pressure maneuver in patients on mechanical ventilation. Jornal Brasileiro de Pneumologia: Publicacao Oficial da Sociedade Brasileira de Pneumologia e Tisilogia 45: e20180058.

Patel ZM, Fernandez-Miranda J, Hwang PH, Nayak JV, Sajjadi RDH et al. (2020). Letter: Precautions for endoscopic transnasal skull base surgery during the COVID-19 pandemic. Neurosurgery 87: E66-E67. DOI 10.1093/neuros/nyaa125.

Pathmanathan N, Beaumont N, Gratrix A (2015). Respiratory physiotherapy in the critical care unit. Continuing Education in Anaesthesia Critical Care \& Pain 15: 20-25. DOI 10.1093/bjaceaccp/mku005.

Plante JA, Plante KS, Gralinski LE, Beall A, Ferris MT et al. (2020). Mucin 4 protects female mice from coronavirus pathogenesis. bioRxiv. DOI 10.1101/2020.02.19.957118.

Poole PJ, Black PN (2003). Mucolytic agents for chronic bronchitis or chronic obstructive pulmonary disease. Cochrane Database of Systematic Reviews 63: 174. DOI 10.1002/14651858.CD001287.

Puchelle E, de Bentzmann S, Zahm JM (1995). Physical and functional properties of airway secretions in cystic fibrosis-therapeutic approaches. Respiration 62: 2-12. DOI 10.1159/000196486.

Puchelle E, Zahm JM, Quemada D (1987). Rheological properties controlling mucociliary frequency and respiratory mucus transport. Biorheology 24: 557-563. DOI 10.3233/BIR-1987-24606.

Quraishi MS, Jones NS, Mason J (1998). The rheology of nasal mucus: A review. Clinical Otolaryngology and Allied Sciences 23: 403413. DOI 10.1046/j.1365-2273.1998.00172.x.

Rajendran RR, Banerjee A (2020). Effect of non-newtonian dynamics on the clearance of mucus from bifurcating lung airway models. Journal of Biomechanical Engineering 143: 56. DOI 10.1115/1.4048474.

Ramos EM, Ramos D, Moreira GL, Macchione M, Guimarães ET et al. (2015). Viscoelastic properties of bronchial mucus after respiratory physiotherapy in subjects with bronchiectasis. Respiratory Care 60: 724-730. DOI 10.4187/respcare.02429.

Ribeiro BS, Lopes AJ, Menezes SLS, Guimarães FS (2019). Selecting the best ventilator hyperinflation technique based on physiologic markers: A randomized controlled crossover study. Heart \& Lung 48: 39-45. DOI 10.1016/j.hrtlng.2018.09.006.

Ridley C, Thornton DJ (2018). Mucins: The frontline defence of the lung. Biochemical Society Transactions 46: 1099-1106. DOI 10.1042/BST20170402.

Robinot R, Hubert M, de Melo GD, Lazarini F, Bruel T et al. (2020). SARS-CoV-2 infection damages airway motile cilia and impairs mucociliary clearance. bioRxiv. DOI 10.1101/2020.10.06.328369.

Rogers D, Doull IJM (2005). Physiological principles of airway clearance techniques used in the physiotherapy management of cystic fibrosis. Current Paediatrics 15: 233-238. DOI 10.1016/j.cupe.2005.02.007.

Rogers DF (2007). Physiology of airway mucus secretion and pathophysiology of hypersecretion. Respiratory Care 52: 1134-1146.

Rogers DF, Barnes PJ (2006). Treatment of airway mucus hypersecretion. Annals of Medicine 38: 116-125. DOI 10.1080/07853890600585795.
Roy MG, Livraghi-Butrico A, Fletcher AA, McElwee MM, Evans SE et al. (2014). Muc5b is required for airway defence. Nature 505: 412-416. DOI 10.1038/nature12807.

Rubin BK, Ramirez O, Zayas JG, Finegan B, King M (1990). Collection and analysis of respiratory mucus from subjects without lung disease. American Review of Respiratory Disease 141: 10401043. DOI 10.1164/ajrccm/141.4_Pt_1.1040.

Safdar N, Crnich CJ, Maki DG (2005). The pathogenesis of ventilatorassociated pneumonia: Its relevance to developing effective strategies for prevention. Respiratory Care 50: 725-739.

Sancho J, Servera E, Vergara P, Marin J (2003). Mechanical insufflationexsufflation $v s$. tracheal suctioning via tracheostomy tubes for patients with amyotrophic lateral sclerosis: A pilot study. American Journal of Physical Medicine \& Rehabilitation 82: 750-753. DOI 10.1097/01.PHM.0000087456.28979.2E.

Sanderson MJ, Sleigh MA (1981). Ciliary activity of cultured rabbit tracheal epithelium: Beat pattern and metachrony. Journal of Cell Science 47: 331-347. DOI 10.1242/jcs.47.1.331.

Saracoglu KT, Saracoglu A, Demirhan R (2020). Airway management strategies for the COVID-19 patients: A brief narrative review. Journal of Clinical Anesthesia 66: 109954. DOI 10.1016/j.jclinane.2020.109954.

Savian C, Paratz J, Davies A (2006). Comparison of the effectiveness of manual and ventilator hyperinflation at different levels of positive end-expiratory pressure in artificially ventilated and intubated intensive care patients. Heart \& Lung 35: 334-341. DOI 10.1016/j.hrtlng.2006.02.003.

Sheehan JK, Thornton DJ, Somerville M, Carlstedt I (1991). The structure and heterogeneity of respiratory mucus glycoproteins. American Review of Respiratory Disease 144: S4-S9. DOI 10.1164/ajrccm/144.3_pt_2.S4.

Shen Y, Huang S, Kang J, Lin J, Lai K et al. (2018). Management of airway mucus hypersecretion in chronic airway inflammatory disease: Chinese expert consensus (English edition). International Journal of Chronic Obstructive Pulmonary Disease 13: 399-407. DOI 10.2147/COPD.

Shih CK, Litt M, Khan MA, Wolf DP (1977). Effect of nondialyzable solids concentration and viscoelasticity on ciliary transport of tracheal mucus. American Review of Respiratory Disease 115: 989-995.

Silberberg A (1983). Biorheological matching: Mucociliary interaction and epithelial clearance. Biorheology 20: 215-222. DOI 10.3233/BIR-1983-20211.

Silberberg A (1990). On mucociliary transport. Biorheology 27: 295307. DOI 10.3233/BIR-1990-273-408.

Sivasothy P, Brown L, Smith IE, Shneerson JM (2001). Effect of manually assisted cough and mechanical insufflation on cough flow of normal subjects, patients with chronic obstructive pulmonary disease (COPD), and patients with respiratory muscle weakness. Thorax 56: 438-444. DOI 10.1136/thx.56.6.438.

Slebos DJ, Shah PL (2017). Collateral Ventilation: Friend or Foe in Patients with Severe Emphysema. Respiration 93: 232-233. DOI 10.1159/000456672.

Sohrabi C, Alsafi Z, O’Neill N, Khan M, Kerwan A et al. (2020). World Health Organization declares global emergency: A review of the 2019 novel coronavirus (COVID-19). International Journal of Surgery 76: 71-76. DOI 10.1016/j. ijsu.2020.02.034.

Spinou A (2018). Non-pharmacological techniques for the extremes of the cough spectrum. Respiratory Physiology \& Neurobiology 257: 5-11. DOI 10.1016/j.resp.2018.03.006. 
Sprung CL, Zimmerman JL, Christian MD, Joynt GM, Hick JL et al. (2010). Recommendations for intensive care unit and hospital preparations for an influenza epidemic or mass disaster: summary report of the European Society of Intensive Care Medicine's Task Force for intensive care unit triage during an influenza epidemic or mass disaster. Intensive Care Medicine 36: 428-443.

Stiller K (2000). Physiotherapy in intensive care: Towards an evidence-based practice. Chest 118: 1801-1813.

Stiller K (2013). Physiotherapy in intensive care: An updated systematic review. Chest 144: 825-847.

Sungnak W, Huang N, Bécavin C, Berg M, Queen R et al. (2020). SARS-CoV-2 entry factors are highly expressed in nasal epithelial cells together with innate immune genes. Nature Medicine 26: 681-687.

Szarpak L, Drozd A, Smereka J (2020). Airway management and ventilation principles in COVID-19 patients. Journal of Clinical Anesthesia 65: 109877.

Tarran R, Button B, Picher M, Paradiso AM, Ribeiro CM et al. (2005). Normal and cystic fibrosis airway surface liquid homeostasis. The effects of phasic shear stress and viral infections. Journal of Biological Chemistry 280: 35751-35759. DOI 10.1074/jbc. M505832200.

Terry PB, Traystman RJ (2016). The clinical significance of collateral ventilation. Annals of the American Thoracic Society 13: 2251-2257. DOI 10.1513/AnnalsATS.201606-448FR.

Terzi N, Prigent H, Lofaso F (2018). Mechanical insufflationexsufflation to improve secretion clearance during invasive ventilation. Respiratory Care 63: 1577-1578. DOI 10.4187/ respcare.06700.

Thomas AJ (2013a). Exercise intervention in the critical care unit what is the evidence? Physical Therapy Reviews 14: 50-59. DOI 10.1179/174328809X405900.

Thomas AJ (2013b). Physiotherapy led early rehabilitation of the patient with critical illness. Physical Therapy Reviews 16: 46-57. DOI 10.1179/1743288X10Y.0000000022.

Thomas P, Baldwin C, Bissett B, Boden I, Gosselink R et al. (2020). Physiotherapy management for COVID-19 in the acute hospital setting: clinical practice recommendations. Journal of Physiotherapy 66: 73-82. DOI 10.1016/j.jphys.2020.03.011.

Thornton DJ, Rousseau K, McGuckin MA (2008). Structure and function of the polymeric mucins in airways mucus. Annual Review of Physiology 70: 459-486. DOI 10.1146/ annurev.physiol.70.113006.100702.

Thornton DJ, Sheehan JK (2004). From mucins to mucus: Toward a more coherent understanding of this essential barrier. Proceedings of the American Thoracic Society 1: 54-61. DOI 10.1513/pats.2306016.

van der Schans C, Postma D, Koeter G, Rubin B (1999). Physiotherapy and bronchial mucus transport. European Respiratory Journal 13: 1477-1486. DOI 10.1183/09031936.99.13614879.

van der Schans CP (2007). Bronchial mucus transport. Respiratory Care 52: 1150-1158.

Vitacca M, Carone M, Clini EM, Paneroni M, Lazzeri M et al. (2020). Joint statement on the role of respiratory rehabilitation in the COVID-19 crisis: The Italian position paper. Respiration 99: 493-499. DOI 10.1159/000508399.

Volpe MS, Adams AB, Amato MB, Marini JJ (2008). Ventilation patterns influence airway secretion movement. Respiratory Care 53: 1287-1294.

Volpe MS, Guimarães FS, Morais CCA (2020). Airway clearance techniques for mechanically ventilated patients: Insights for optimization. Respiratory Care 65: 1174-1188. DOI 10.4187/ respcare.07904.

Volsko TA (2013). Airway clearance therapy: Finding the evidence. Respiratory Care 58: 1669-1678. DOI 10.4187/respcare.02590.

Volsko TA, DiFiore J, Chatburn RL (2003). Performance comparison of two oscillating positive expiratory pressure devices: Acapella versus Flutter. Respiratory Care 48: 124-130.

Wang J, Luo M, Liu Z, Jin Y, Liang S et al. (2017). Influence of $\mathrm{Fe}_{2} \mathrm{O}_{3}$ nanoparticles on the rhological properties of simulated asthma airway mucus. Journal of Biomedical Engineering 34: 193-199.

Wang Y, Zhang M, Yu Y, Han T, Zhou J, Bi L (2020). Sputum characteristics and airway clearance methods in patients with severe COVID-19. Medicine 99: e23257. DOI 10.1097/ MD.0000000000023257.

Widdicombe J (1997). Airway and alveolar permeability and surface liquid thickness: Theory. Journal of Applied Physiology 82: 312. DOI 10.1152/jappl.1997.82.1.3.

Wilson LM, Morrison L, Robinson KA (2019). Airway clearance techniques for cystic fibrosis: An overview of Cochrane systematic reviews. Cochrane Database of Systematic Reviews 1: 171. DOI 10.1002/14651858.CD011231.pub2.

Winters SL, Davis CW, Boucher RC (2007). Mechanosensitivity of mouse tracheal ciliary beat frequency: Roles for $\mathrm{Ca}^{2+}$, purinergic signaling, tonicity, and viscosity. American Journal of Physiology-Lung Cellular and Molecular Physiology 292: L614-L624. DOI 10.1152/ajplung.00288.2005.

Winters SL, Yeates DB (1997). Roles of hydration, sodium, and chloride in regulation of canine mucociliary transport system. Journal of Applied Physiology 83: 1360-1369. DOI 10.1152/jappl.1997.83.4.1360.

Wu C, Chen X, Cai Y, Xia Ja, Zhou X et al. (2020). Risk factors associated with acute respiratory distress syndrome and death in patients with coronavirus disease 2019 pneumonia in Wuhan, China. JAMA Internal Medicine 180: 934. DOI 10.1001/jamainternmed.2020.0994.

Wu Z, McGoogan JM (2020). Characteristics of and important lessons from the coronavirus disease 2019 (COVID-19) outbreak in China: Summary of a report of 72314 cases from the Chinese center for disease control and prevention. JAMA 323: 1239-1242. DOI 10.1001/jama.2020.2648.

Xie J, Tong Z, Guan X, Du B, Qiu H, Slutsky AS (2020). Critical care crisis and some recommendations during the COVID-19 epidemic in China. Intensive Care Medicine 46: 837-840. DOI 10.1007/s00134-020-05979-7.

Xu L, Jiang Y (2019b). Mathematical modeling of mucociliary clearance: A mini-review. Cells 8: 736. DOI 10.3390/cells8070736.

Xu Z, Shi L, Wang Y, Zhang J, Huang L et al. (2020). Pathological findings of COVID-19 associated with acute respiratory distress syndrome. Lancet Respiratory Medicine 8: 420-422. DOI 10.1016/S2213-2600(20)30076-X.

Yam LY, Chen RC, Zhong NS (2003). SARS: Ventilatory and intensive care. Respirology 8: S31-S35. DOI 10.1046/j.14401843.2003.00521.x.

Yang X, Yu Y, Xu J, Shu H, Xia Ja et al. (2020). Clinical course and outcomes of critically ill patients with SARS-CoV-2 pneumonia in Wuhan, China: A single-centered, retrospective, observational study. The Lancet Respiratory Medicine. Lancet Respiratory Medicine 8: 475-481. DOI 10.1016/S2213-2600 (20)30079-5. 
Ye Q, Wang B, Mao J (2020). The pathogenesis and treatment of the 'Cytokine Storm' in COVID-19. Journal of Infection 80: 607613. DOI 10.1016/j.jinf.2020.03.037.

Zahm JM, Pierrot D, Vaquez-Girod S, Duvivier C, King M et al. (1989). The role of mucus sol phase in clearance by simulated cough. Biorheology 26: 747-752. DOI 10.3233/ BIR-1989-26407.

Zayas G, Dimitry J, Zayas A, O’Brien D, King M (2005). A new paradigm in respiratory hygiene: Increasing the cohesivity of airway secretions to improve cough interaction and reduce aerosol dispersion. BMC Pulmonary Medicine 5: 1155. DOI 10.1186/1471-2466-5-11.

Zhang Z, Wang T, Liu F, Zhu A, Gu G et al. (2021). The proteomic characteristics of airway mucus from critical ill COVID-19 patients. Life Sciences 269: 119046. DOI 10.1016/j.lfs.2021.119046.

Zhu N, Zhang D, Wang W, Li X, Yang B et al. (2020). A novel coronavirus from patients with pneumonia in China. 2019 New England Journal of Medicine 382: 727-733. DOI 10.1056/NEJMoa2001017.
Ziegler CGK, Allon SJ, Nyquist SK, Mbano IM, Miao VN et al. (2020). SARS-CoV-2 receptor ACE2 is an interferonstimulated gene in human airway epithelial cells and is detected in specific cell subsets across tissues. Cell 181: 1016-1035.e19. DOI 10.1016/j.cell.2020.04.035.

Zou X, Chen K, Zou J, Han P, Hao J et al. (2020). Single-cell RNA-seq data analysis on the receptor ACE2 expression reveals the potential risk of different human organs vulnerable to 2019-nCoV infection. Frontiers of Medicine 14: 185-192. DOI 10.1007/s11684-020-0754-0.

França EÉTd, Ferrari F, Fernandes P, Cavalcanti R, Duarte A et al. (2012). Physical therapy in critically ill adult patients: Recommendations from the Brazilian Association of Intensive Care Medicine Department of Physical Therapy. Revista Brasileira de Terapia Intensiva 24: 6-22.

McIlwaine M, Bradley J, Elborn JS, Moran F, Liang S (2017). Personalising airway clearance in chronic lung disease. European Respiratory Review: An Official Journal of the European Respiratory Society 26: 160086.

\section{TABLE S1}

Physiological basis of ACTs (França et al., 2012; McIlwaine et al., 2017)

\begin{tabular}{|c|c|c|c|c|c|c|}
\hline \multirow[t]{2}{*}{ ACTs } & & \multicolumn{2}{|c|}{ Ventilation to obstructed regions } & \multicolumn{2}{|c|}{ Expiratory airflow } & \multirow[t]{2}{*}{ Oscillation } \\
\hline & & Interdependence & $\mathrm{CV}$ & PEF & Bias flow & \\
\hline Postural drainage & & Yes & Yes & Yes & Yes & No \\
\hline \multirow[t]{5}{*}{ Breathing maneuvers } & 3-s breathing holds & Yes & Yes & No & Yes & No \\
\hline & Thoracic expansion exercises & Yes & Yes & No & No & No \\
\hline & Mobilization & Yes & Yes & No & No & No \\
\hline & Forced expiratory techniques & No & No & Yes & Yes & No \\
\hline & Autogenic drainage & No & Yes & Yes & Yes & No \\
\hline \multirow[t]{3}{*}{ PEP } & Traditional & No & Yes & Yes & Yes & No \\
\hline & Oscillating PEP with Flutter & Oscillation at $>3 \mathrm{~Hz}$ & Yes & Yes & Yes & $2-32 \mathrm{~Hz}$ \\
\hline & Oscillating PEP with Acapella & No & Yes & Yes & Yes & $10-18 \mathrm{~Hz}$ \\
\hline Percussion & & No & No & Yes & No & Yes \\
\hline HFCWO & & Oscillation at $>3 \mathrm{~Hz}$ & No & Yes & Yes & $5-25 \mathrm{~Hz}$ \\
\hline \multirow[t]{2}{*}{ Lung hyperinflation } & MHI & Yes & Yes & Yes & Yes & No \\
\hline & VHI & Yes & Yes & Yes & Yes & No \\
\hline MI-E & & Yes & Yes & Yes & Yes & No \\
\hline
\end{tabular}

Note: CV: collateral ventilation; HFCWO: high frequency chest wall oscillation; PEF: peak expiratory flow rate; PEP: positive expiratory pressure; PIF: peak inspiratory flow rate; MHI: manual hyperinflation; VHI: ventilator hyperinflation; MI-E: mechanical insulfflation-exsufflation. 